\title{
LITERACY REQUIREMENTS OF COURT DOCUMENTS: AN UNDER-EXPLORED BARRIER TO ACCESS TO JUSTICE
}

\author{
Amy Salyzyn \\ Lori Isaj \\ Brandon Piva \\ Jacquelyn Burkell*
}

We know that members of the public find court forms complex. Less is known, however, about what in particular makes these documents difficult for non-legally trained people to complete.

The study described in this article seeks to fill this information gap by deploying a "functional literacy" framework to evaluate court form complexity. In contrast to more traditional conceptions of literacy, "functional literacy" shifts the focus away from the ability to read and towards the ability of individuals to meet task demands. Under this framework, an individual is assigned a literacy level by virtue of the complexity of the tasks that he or she is able to complete. As a result, the framework focuses as much on tasks (and associated documents) as it does on the capacity of the individual.

Four different Ontario forms needed to initiate three different types of legal proceedings were examined. The results of the study are described in significant detail in the article. Some of the identified sources of challenge include requirements to: generate information that requires expert legal knowledge; infer the meaning of technical legal terms; and move between multiple information sources (including, for example, searching on a website to find a correct court address). Another set of identified challenges was reflected in "distractors" contained in the court forms that risked confusing the reader, such as broad requests for information or the use of unclear terms. Although the associated court guides provided some guidance on the above types of issues, we found that such guidance was often incomplete and also potentially difficult to access given the overall complexity of the guides themselves.

Although proposing comprehensive solutions was beyond the scope of this study, the article concludes with a preliminary discussion of possible solutions, including form redesign, the use of dynamic electronic forms and the provision of unbundled legal services.

Amy Salyzyn is Assistant Professor in the Faculty of Common Law at the University of Ottawa; Jacquelyn Burkell is Associate Professor in the Faculty of Information and Media Studies at Western University; Lori Isaj, a JD candidate at the University of Ottawa, and Brandon Piva, a JD candidate at the University of Ottawa, acted as research assistants on this project and conducted the functional literacy analyses discussed herein. The authors would like to thank Nicole Aylwin, Noel Semple, and Julie Macfarlane for their thoughtful feedback on an earlier draft of this article. 
Nous savons que les membres du public trouvent les formulaires juridiques complexes. Ce qui est moins connu, par contre, ce sont les raisons particulières qui rendent ces documents difficiles à remplir pour les personnes n'ayant aucune formation juridique.

L'étude décrite dans cet article vise à répondre à cette interrogation au moyen d'un cadre d'" alphabétisme fonctionnel " permettant d'évaluer la complexité des formulaires juridiques. Contrairement aux conceptions habituelles de l'alphabétisme, l'« alphabétisme fonctionnel » se définit davantage comme la capacité d'une personne de répondre aux exigences d'une tâche que comme sa capacité de lire. Dans ce cadre, on attribue à une personne un niveau d'alphabétisme selon la complexité des tâches qu'elle est capable d'effectuer. En conséquence, le cadre utilisé porte autant sur les tâches (et les documents qui y sont associés) que sur la capacité de la personne.

Quatre formulaires requis pour introduire trois différents types d'instance en Ontario ont fait l'objet de cette étude. Les résultats sont décrits en détails assez abondants dans l'article. Parmi les sources de difficulté décelées, mentionnons la nécessité de produire de l'information qui nécessite des connaissances juridiques spécialisées, la nécessité de déduire le sens de termes juridiques spécialisés et la nécessité de consulter de multiples sources d'information (par exemple, faire des recherches sur un site Web pour trouver la bonne adresse du palais de justice). Citons également les "éléments distracteurs » qui se trouvent dans les formulaires juridiques et qui risquent de semer la confusion chez le lecteur, comme des demandes très générales d'information ou l'emploi de termes imprécis. Bien que les guides accompagnant ces formulaires donnent quelques conseils sur les difficultés mentionnées, nous avons conclu que ces conseils étaient souvent incomplets et pouvaient être peu accessibles en raison de la complexité générale de ces mêmes guides.

Certes, cette étude ne comprenait pas la proposition de solutions générales mais elle se conclut par un débat préliminaire de solutions possibles, dont une refonte des formulaires, l'utilisation de formulaires électroniques dynamiques et la prestation de services juridiques dégroupés.

\section{INTRODUCTION}

Court forms are complex. Canadians have told researchers this in numerous studies to date. For individuals who can afford lawyers, court form complexity may result in few, if any, adverse consequences as the legal professionals representing them have the experience and training to navigate these documents with relative ease. The story is different, however, for the increasing number of individuals who end up representing themselves in court because they cannot afford a lawyer. For those individuals, commonly referred to as "self-represented litigants" [SRLs], court form complexity can be a major barrier to accessing justice. As a practical matter, if SRLs have difficulty in understanding or completing a court form, their legal rights may be compromised. Complexity can lead to mistakes in completing court forms or, in some cases, even be so challenging or demoralizing that an individual may choose not to pursue or defend a claim. Systemically, court form complexity can lead to significant 
delay if court staff and judges need to spend time explaining court forms or dealing with the consequences of forms that are incorrectly filled out. The stakes are high.

Although there are multiple studies confirming that members of the public perceive court forms to be complex, there is little study of what, specifically, can make completing a court form difficult for people. The study discussed in this article aims to fill this knowledge gap by deploying a "functional literacy" framework to evaluate court form complexity. In contrast to more traditional conceptions of literacy, "functional literacy" shifts the focus away from the ability to read and towards the ability of individuals to meet task demands. Under this framework, an individual is assigned a literacy level by virtue of the complexity of the tasks that he or she is able to complete. As a result, the framework focuses as much on the tasks (and associated documents) as it does on the capacity of the individual.

In focusing on tasks, the functional literacy approach acknowledges that "[a]dults do not read printed materials in a vacuum but read them within a context or for a particular purpose." ${ }^{1}$ The contextual and purposive focus of the functional literacy approach makes it particularly well suited to evaluating court forms - documents that involve a series of tasks for individuals to complete in a particular context and for a particular purpose. Rather than simply indicating whether or not an individual has the vocabulary to understand the words contained in a document, the functional literacy approach "allows information designers to estimate and predict the difficulty of the tasks that we expect from readers."

Insofar as it focuses on the difficulty of tasks, the functional literacy approach can also highlight solutions that involve reducing the complexity of tasks and "fixing" the document at issue rather than looking only to "fix" the individuals who might use the document by improving their literacy levels through training and education. In other words, "[b]y understanding literacy complexity factors, information designers can produce better documents that are accessible and usable by as many people as possible."

The study described in this article evaluated the complexity of four different Ontario forms needed to initiate three different types of legal proceedings: (1) a Plaintiff's Claim (Form 7A) that an individual would need to start a claim in Small Claims Court; (2) an Application about Tenant Rights (Form T2) that an individual would need to seek relief against a landlord before the Landlord and Tenant Board; and (3) a Divorce Application (general) (Form 8) and Financial Statement (property and support claims) (Form 13.1) that an individual would need to seek a contested divorce, which would include a contested spousal support claim and division of property. Although the Landlord and Tenant Board is properly described as a tribunal as opposed to a court, the term "court forms" will be used throughout this article for ease of reference. With respect to each court form, it was assumed for the purposes of this study that the individual using the court form would also be referring to the relevant government-published guide to completing the specific court form. Both the court forms and the guides examined were those in use as of July 2015.

As discussed above, the concept of functional literacy focuses on the ability of individuals to meet task demands. Logically, this opens up two avenues of assessment and intervention: (1) assessing the literacy levels of individuals and intervening to increase those literacy levels; or (2) assessing the

Julian Evetts \& Michel Gauthier, Literacy Task Assessment Guide (Ottawa: National Literacy Secretariat, 2005) at 3.

Ibid.

Ibid. 
literacy requirements of task/document pairings and intervening to reduce task/document complexity and, thus, the associated literacy level requirements. Most literacy assessment tools (such as the tool developed by the Program for the International Assessment of Adult Competencies used in the most recent initiative of the Organisation for Economic Co-operation and Development to measure international literacy levels ${ }^{4}$ ) focus on measuring the literacy level of individuals rather than measuring the literacy demands arising from the combination of task and documents. One exception to this rule, and, indeed, the only exception we have been able to identify, is a rating tool developed by Julian Evetts and Michel Gauthier and published in the 2005 Literacy Task Assessment Guide that they authored. ${ }^{5}$

This rating tool assesses the complexity of task/document pairing - that is, it identifies the literacy level that an individual would require to be able to complete a specific task reliably given a specific set of documents. The rating tool, in brief, measures the difficulty of tasks looking at several different factors: (1) the overall document complexity (organization and structure); (2) the type of information being requested (how concrete versus how abstract); and (3) "the type of cognitive processing strategies, and their processing conditions" (looking at, for example, how many sources of information must an individual look at to prepare a relevant response or whether there is terminology used that may be confusing for an individual). ${ }^{6}$ Using this rating tool, we evaluated the complexity of each task contained in the court forms - 282 tasks in total - assigning a numeric score reflecting the complexity of each individual task in the form. This numeric score can, in turn, be used to estimate the minimum level of functional literacy that a person would likely need to complete the task. The specific process of using the rating tool to evaluate task complexity is very detailed and is described in greater detail below. ${ }^{7}$

In addition to producing this type of quantitative data, the process of using the rating tool also yielded general observations about the recurring issues in court forms that contributed to increased complexity. Identified sources of challenge include requirements to: generate information that requires expert legal knowledge; infer the meaning of technical legal terms; and move between multiple information sources (including, for example, searching on a website to find a correct court address). Another set of challenges identified was reflected in the "distractors" contained in the court forms that risked confusing the reader, such as broad requests for information or the use of unclear terms. Although the associated court guides provided some guidance on the above types of issues, we found that such guidance was often incomplete and also potentially difficult to access given the overall complexity of the guides themselves. The descriptive outcomes discussed in this paragraph are addressed in detail below.

This article proceeds in six parts. In the first part of the article, the context to this study is set out with a review of Canada's ongoing access-to-justice crisis and the rise of SRLs in Canadian courts. This part also summarizes previous studies in which SRLs have described court form complexity as one barrier that they have experienced to effectively accessing courts. Julie Macfarlane's ground-breaking study of

4 Statistics Canada, Skills in Canada: First Results from the PIAAC, 2012, Catalogue no 89-555-X (Ottawa: Tourism and the Centre for Education Statistics Division, 2013) at 16 [Statistics Canada, Skills in Canada]; Statistics Canada, Building on Our Competencies: Canadian Results of the International Adult Literacy and Skills Survey, 2003, Catalogue no 89-617-XIE (Ottawa: Statistics Canada, 2005) [Statistics Canada, Building on Our Competencies].

Evetts \& Gauthier, supra note 1.

$6 \quad$ Ibid at 5.

7 For a comprehensive understanding of how the rating tool operates, please see $i b i d$ at 55-66. 
the SRL experience in Canada is highlighted. The second part of the article observes the general absence of research of what, in particular, makes court forms difficult for SRLs to complete in the Canadian context, with the Divorce Applications Project and the Court Guides Assessment Project that formed part of Macfarlane's study and a recent project on Yukon court forms headed by the Winkler Institute for Dispute Resolution discussed as exceptions. The third and fourth parts form the heart of this article, describing, respectively, the functional literacy framework and the methodology and results of the study. The fifth part addresses potential concerns arising from inherent limitations in the methodology used in this study, and the sixth part then briefly concludes with a preliminary discussion of possible solutions, including form redesign, the use of dynamic electronic forms, and the provision of unbundled legal services.

\section{COURT FORMS AS A BARRIER TO ACCESS TO JUSTICE}

Canada's ongoing access-to-justice crisis has, for many years now, been the subject of significant commentary and concern. ${ }^{8}$ Chief Justice Beverley McLachlin has repeatedly made access to justice and the need to improve it a centerpiece of her public speeches. ${ }^{9}$ The Chief Justice is by no means alone in her attention to this issue. A significant number of other Canadian judges, legal organizations, lawyers, and academics have dedicated substantial time and effort to studying and proposing solutions for Canada's access-to-justice problem. ${ }^{10}$ Although there is dispute about the specific nature of Canada's access-to-justice problem, one repeatedly cited concern has been the unaffordability of retaining a lawyer and the resulting rise of SRLs in Canadian courts. ${ }^{11}$ In 2013, Julie Macfarlane published a

8 For a helpful account of how access to justice has been conceptualized in the Canadian dialogue, see, $e$ g, Jane Bailey, Jacquelyn Burkell \& Graham Reynolds, “Access to Justice for All: Towards an 'Expansive Vision' of Justice and Technology" (2013) 31 Windsor YB Access Just 181.

9 See, e g, Right Honourable Beverley McLachlin, "The Legal Profession in the 21 st Century" (Remarks delivered at the 2015 Canadian Bar Association Plenary, 14 August 2015), online: National Magazine

$<$ http://www.nationalmagazine.ca/NationalMagazine/media/MediaLibrary/pdf/2015-08-mclachlin.pdf>; Ian Bailey, "Public Faces Barriers in Accessing Canadian Courts, Chief Justice Says," Globe and Mail (13 August 2012), online: $<$ http://www.theglobeandmail.com/news/british-columbia/public-faces-barriers-in-accessing-canadian-courts-chiefjustice-says/article4476757/>.

10 For a small subset of the commentary on this issue, see, $e$ g, Chief Justice George Strathy, "Remarks of Chief Justice George Strathy" (Address delivered at the Opening of Courts of Ontario, 24 September, 2015), online: Court of Appeal for Ontario <http://www.ontariocourts.ca/coa/en/ps/ocs/ocs.htm>; James Bradshaw, "Ontario Courts 'Only Open to the Rich,' Judge Warns," Globe and Mail (2 July 2013), online: <http://www.theglobeandmail.com/news/national/ontariocourts-only-open-to-the-rich-judge-warns/article12942343/>; Canadian Bar Association, "Reaching Equal Justice: An Invitation to Envision and Act," online: <http://www.cba.org/cba/equaljustice/secure_pdf/Equal-Justice-Reporteng.pdf>; Action Group on Access to Justice, "TAG - The Action Group on Access to Justice," online: Law Society of Upper Canada <http:// http://www.lsuc.on.ca/TAG/>; Action Group on Access to Justice, "Legal Organizations and Access to Justice Initiatives in Ontario" (2014), online: The Law Society of Upper Canada $<$ http://www.lsuc.on.ca/uploadedFiles/BackgrounderonLegalOrganizationsasofMay282014ENGFINAL.pdf $>$; Trevor CW Farrow, "What Is Access to Justice?" (2014) 51 Osgoode Hall LJ 957; Michael Trebilcock, Anthony Duggan \& Lorne Sossin, eds, Middle Income Access to Justice (Toronto: University of Toronto Press, 2012).

11 Rachel Birnbaum, Nicholas Bala \& Lorne Bertrand, "The Rise of Self-Representation in Canada's Family Courts: The Complex Picture Revealed in Surveys of Judges, Lawyers \& Litigants” (2013) 91 Can Bar Rev 67; Mary Stratton, 
ground-breaking and comprehensive study of SRLs that confirmed that an "extraordinary" number of individuals are now self-represented in Canadian courts. ${ }^{12}$ Her research revealed that the percentage of litigants appearing without counsel in provincial family court "is consistently at or above $40 \%$, and in some cases far higher" and that more than 70 percent of litigants are self-represented in some lowerlevel civil courts. ${ }^{13}$ Macfarlane's study also confirmed what many had suspected: the most common reason for self-representation is "the inability to afford to retain, or to continue to retain, legal counsel." ${ }^{14}$ Over 90 percent of the respondents to her study "referred in some way to financial reasons for representing themselves." 15

Once engaged in court proceedings, SRLs face numerous barriers and challenges ${ }^{16}$ Court forms are one identified source of significant frustration. Many of the respondents in Macfarlane's study reported that they found court forms difficult to complete. ${ }^{17}$ Among the reported challenges were difficulties in determining which court forms were necessary to complete and the receipt of contradictory information from court staff about the forms. ${ }^{18}$ The forms themselves were also a major source of complaint. As summarized in the report,

[v]irtually every SRL in the sample complained that they found the language in the court forms confusing, complex and, and some cases, simply incomprehensible - referring to terms and concepts with which they were unfamiliar. This reaction was the same across all types of litigant no matter what court or province they filed in (although there were somewhat fewer complaints about small claims court forms and procedures, these were not devoid of criticism either). ${ }^{19}$

The observations contained in Macfarlane's report about the complexity of court forms have been echoed in other surveys of SRLs. For example, the seven SRL respondents interviewed for a 2004 British Columbia mapping study of SRL services and gaps reported the following with respect to court forms:

“Alberta Self-Represented Litigants Mapping Project: Final Report" (2007), online: Canadian Forum on Civil Justice $<$ http://www.cfcj-fcjc.org/sites/default/files/docs/2007/mapping-en.pdf $>$; Richard Devlin, "Breach of Contract?: The New Economy, Access to Justice and the Ethical Responsibilities of the Legal Profession" (2002) Dal LJ 355 (QL); David W Scott, "The Plight of the Self-Represented Litigant" (2007) 26 Advocates' Society J 8 (QL).

12 Julie Macfarlane, "The National Self-Represented Litigants Project: Identifying and Meeting the Needs of SelfRepresented Litigants" (2013) at 32, online: Law Society of Upper Canada $<\mathrm{http}$ //www.lsuc.on.ca/uploadedFiles/For_the_Public/About_the_Law_Society/Convocation_Decisions/2014/Selfrepresented_project.pdf $>$.

13 Ibid.

14 Ibid at 8.

$15 \quad$ Ibid at 39.

16 Ibid.

17 Ibid at 59-62.

18 Ibid.

19 Ibid. 
The fifth time I did the first form I was able to file it ... I didn't just do a chambers application. I had to do a bill of costs and I didn't understand that at all.

When I did the final application for sole custody, it took two months. It had to work.

I didn't have anyone to help write the affidavit. I didn't know what to put in it. I just had the body of one.

What I would have liked would have been able to go with the form I had to respond to and sit down with someone and ask, where to start? That would have been more than helpful.

If you have someone to help you with the forms, you won't be going back four times and that's got to save time at the registry. It's very complex and there is alot [sic] of back and forth. $^{20}$

Surveys of SRLs involved in family law proceedings suggest that family law forms pose particular challenges for those without legal representation. Respondents to a 2012 study of Ontario family law litigants reported frustrations with the court forms that they encountered, stating, among other things:

The forms you are given to fill out are extremely difficult to understand. They are designed for lawyers to fill out and not regular people presenting themselves.

Can't fill the forms, no one wants to help ... tried to get lawyer and too much income. ${ }^{21}$

More than 50 percent of respondents to another study of Ontario family law litigants reported that they "found difficulties with the court forms and knowing their legal rights."22

Confirming information received from SRLs themselves, court staff members have also noted challenges with court forms. In one national study, 97 percent of court staff surveyed agreed that SRLs required help with completing court forms. ${ }^{23}$ More colourfully, a "veteran courthouse manager" surveyed for Macfarlane's study stated:

20 Gayla Reid, Donna Senniw \& John Malcolmson, "Developing Models for Coordinated Services for Self-Representing Litigants: Mapping Services, Gaps, Issues and Needs" (2004) at 47, online: Justice Education

$<$ http://www.justiceeducation.ca/themes/framework/documents/srl_mapping_repo.pdf $>$.

21 Rachel Birnbaum \& Nicholas Bala, "Experiences of Ontario Family Litigants with Self-Representation" (2012) at 9, online: Pro Bono Students Canada $<$ http:// http://www.probonostudents.ca/>.

22 Anne-Marie Langan, "Threatening the Balance of the Scales of Justice: Unrepresented Litigants in the Family Courts of Ontario" (2005) 30 Queen's LJ 825 at para 15.

23 Trevor Farrow et al, "Addressing the Needs of Self-Represented Litigants in the Canadian Justice System: A White Paper Prepared for the Association of Canadian Court Administrators" (2012) at 65, online: Canadian Forum on Civil Justice <http://www.cfcj-fcjc.org/sites/default/files/docs/2012/Addressing\%20the\%20Needs\%20of\%20SRLs\%20ACCA\%20White\%20Paper\%20March\%202012\%20Final\%20Revised\%20Version.pdf>. 
The forms are ridiculous. The lawyers can't do it either. It creates more work for the counter staff. In Queens Bench it got so bad that we gave up using the four different forms and instead created our own single affidavit system. ${ }^{24}$

The issue of court form complexity is by no means restricted to the Canadian court system. A 2011 Michigan report, for example, observes that court forms used in that jurisdiction "have always used legal language familiar to attorneys and judges" and that "they are difficult if not impossible for persons without legal training to understand." ${ }^{25}$ Similarly, a 2001 New Mexico report notes that, although the increased use of forms has been seen by courts as one way to assist the self-represented, "[f]orms by themselves ... are still to difficult for many pro se litigants ... [who] have trouble with common legal definitions, do not understand what to put in blank spaces, and often fail to understand the proper sequence for multiple forms. ${ }^{, 26}$ Similar reports can be found with respect to other states. ${ }^{27}$ As is true with respect to their Canadian counterparts, it is clear that American SRLs often find court forms "overwhelming., 28

Additionally, reports from England and Wales and Australia confirm that court form complexity is a problem in common law jurisdictions outside of North America. A 2011 report authored by the English Civil Justice Council for the Lord Chancellor and the Lord Chief Justice reported the following challenges with court forms:

- It can be difficult to obtain court forms or find them. Often you first have to know the name or number of the form, and to be able to ascertain that it is the one you need.

- They are all not easy to follow ... expressions like "fast track" or "multi track" or "execution of warrant" have no meaning to a first-time user.

24 Macfarlane, supra note 12 at 62.

25 John M Greacen, "Resources to Assist Self-Represented Litigants: A Fifty-State Review of the "State of the Art", (2011) at 22, online: Michigan State Bar Foundation < http://www.msbf.org/selfhelp/GreacenReportNationalEdition.pdf>.

26 Pamela B Minzner \& Gregory T Ireland, “The Self-Represented Litigant Working Group: Final Report” (2001) at 11, online: New Mexico Courts

$<$ https://www.nmcourts.gov/newface/access2justice/2001_srl_report_minzner_and_ireland.pdf $>$.

27 Judge Denise S Owens, "The Reality of Pro Se Representation" (2013) at 147, online: Mississippi Law Journal $<$ http://mississippilawjournal.org/wp-content/uploads/2014/11/Owens_82MissLJSupra147.pdf >; Delaware Supreme Court, "Delaware Courts: Fairness for All Task Force" (2009), online:

$<$ http://courts.delaware.gov/docs/FAIRNESSFINALREPORT.pdf>; Bonnie Rose Hough, "Description of California Courts' Programs for Self-Represented Litigants" (2004) 11 Intl J Legal Prof 321; John M Greacen, "Report on the Programs to Assist Self Represented Litigants of the State of Maryland” (2004), online: < http://www.courts.delaware.gov/AOC/Doc-ket/Winter2009/fairness.aspx >.

28 Rochelle Klempner, "The Case for Court-based Document Assembly Programs: A Review of the New York State Court Systems 'DIY' Forms" 41 Fordham Urb LJ 1196; Wisconsin Pro Se Working Group, "Meeting the Challenge of SelfRepresented Litigants in Wisconsin" (2000) at 27, online: $<$ https:/www.wicourts.gov/publications/reports/docs/prosereport.pdf $>$. 
- They often contain only limited procedural guidance. ${ }^{29}$

Australian studies have also confirmed that SRLs require assistance with court forms. Respondents involved in a Queensland study identified the preparation of court forms and documents as one of the top three barriers to having their case heard properly. ${ }^{30}$

Beyond making legal proceedings frustrating and unpleasant, overly complex court forms can have devastating consequences for SRLs. In some cases, SRLs may become too overwhelmed with the necessary paperwork and, as a result, abandon pursuing or defending a court case. ${ }^{31}$ The legal rights of SRLs can also be detrimentally impacted when court forms are not completed properly due to difficulties in understanding what the court forms require. ${ }^{32}$

\section{PREVIOUS STUDIES OF WHAT MAKES COURT FORMS COMPLEX}

As discussed above, there is considerable testimonial evidence suggesting that court forms are too complex for many non-legally trained individuals to complete. Both SRLs and court staff have discussed this complexity when interviewed for several studies. There appears, however, to be little study of what, in particular, makes court forms difficult for self-represented parties to complete in the Canadian context. Two important exceptions are the Divorce Applications Project and the Court Guides Assessment Project that formed part of Macfarlane's 2013 study. The Divorce Applications Project involved a law student completing the forms required for divorce in Alberta, British Columbia, and Ontario, keeping a log of time spent and recording comments about her experience. Among other things, the student observed difficult language and terminology, challenges in picking the correct forms to fill out, the overwhelming amount of detail required in some cases, and repeated references to undefined terms like "supporting documentation" or "service.",33

The Court Guides Assessment Project involved a different approach; an information technology specialist evaluated three court guides using the following criteria:

- does the material use accessible and easily understood language;

- does the material avoid technical and legal jargon;

- is the use of language and terms consistent throughout the guide;

- do there seem to be any important unanswered questions;

29 Robin Knowles et al "Access to Justice for Litigants in Person (or Self-Represented Litigants)" (2011) at 65, online: Courts and Tribunals Judiciary < https://www.judiciary.gov.uk/wp-content/uploads/2014/05/report-on-access-to-justicefor-litigants-in-person-nov2011.pdf $>$.

30 Elizabeth Richardson, Tania Sourdin \& Nerida Wallace, "Self-Represented Litigants: Gathering Useful Information," Final Report (2012) at 82, online: Civil Justice Research Online $<$ http://www.civiljustice.info/cgi/viewcontent.cgi?article=1001\& context=srl $>$.

31 See, e g, Macfarlane, supra note 12 at 50 (stating that "[s]ome SRL's began with a sense of confidence, which usually drained away quickly when faced with the reality of the court process, often triggered by difficulties completing application forms and understanding the service process").

32 Ibid at 61 (referencing "significant consequences" arising from incomplete or incorrectly completed court forms).

33 Ibid at $56-59$. 
- is there a reference point for further questions;

- what is the material's "reading level"; and

- what is the experience of navigating among the uniform resource locators (URL) cited in order to complete the form?

Among other things, this assessment revealed:

- unclear grammatical expression;

- technical terms that are not explained;

- vague or incomplete guidance; and

- a wide variance in reading levels. ${ }^{34}$

Additionally, in 2015, Nicole Aylwin, in her capacity as assistant director for the Winkler Institute for Dispute Resolution, engaged in a human-centred design approach to improving and simplifying family court forms in Yukon, which involved engaging directly with self-represented litigants and other justice system stakeholders to redesign the family law statement of claim used in that territory. ${ }^{35}$ A final report on this project is forthcoming but was not publicly available at the time of writing.

Outside the Canadian context, there have been some additional studies regarding court form complexity, many of which have focused on assessing court forms against readability standards. ${ }^{36}$ Broadly speaking, measuring readability reflects more traditional approaches to literacy, which focus on the ability of an individual to understand the words they are reading (in terms, for example, of vocabulary and complexity of sentence structure). As will be discussed in greater detail in the section below, the functional literacy approach distinctly focuses on task complexity.

\section{THE FUNCTIONAL LITERACY FRAMEWORK}

The aim of the study discussed in the fifth section below is to build on the work contained in previous studies by examining the accessibility of court forms using a functional literacy framework. Before discussing the methodology and results of our study, this part will first review the background and key features of the functional literacy approach and outline some of the available data about the functional literacy levels of Canadians. Although its origins can be traced to as early as the 1930s, the functional literacy framework more recently became prominent because it was used in the International Adult

Ibid at 66.

35 Winkler Institute for Dispute Resolution, "Yukon Simplified Court Forms," online:

$<$ https://winklerinstitute.ca/projects/featured-content-center/>.

36 See, eg, Charles R Dyer et al, "Improving Access to Justice: Plain Language Family Law Court Forms in Washington State" (2013) 11 Seattle J Social Just 1065; Ronald W Staudt \& Paula L Hannafordt, "Access to Justice for the SelfRepresented Litigant: An Interdisciplinary Investigation by Designers and Lawyers" (2002) 52 Syracuse L Rev 1017. 
Literacy Study [IALS]. ${ }^{37}$ The IALS was "a large-scale co-operative effort by governments, national statistical agencies, research institutions and the Organisation for Economic Co-operation and Development [OECD]" that involved literacy studies taking place between 1994 and 1998 and that eventually grew to involve twenty countries, including Canada. ${ }^{38}$ Two major respects in which the IALS was notable were: (1) its ambition insofar as it "fielded the world's first large-scale comparative assessment of adult literacy;", ${ }^{39}$ and (2) its focus away from understanding literacy "as a condition that adults either have or do not have" and towards a definition of literacy "as a particular capacity and mode of behavior." 40

To elaborate on this second point, the IALS rejected the approach to literacy that had been adopted by many previous studies - namely, "defin[ing] literacy in terms of a number of completed years of schooling or a grade-level score on school-based reading tests." ${ }^{.41}$ Instead of this conventional definition, the IALS defined literacy as "the ability to understand and employ printed information in daily activities, at home, at work and in the community - to achieve one's goals, and to develop one's knowledge and potential. ${ }^{, 42}$ In other words, a more functional approach to literacy was adopted. As mentioned in the introduction, a key feature of the functional literacy approach is that it assigns a literacy level to individuals by virtue of the complexity of the tasks that they are able to complete. The IALS "employed a sophisticated methodology" to measure literacy proficiency on a numerical scale ranging from 0 to 500 points. ${ }^{43}$ These points were then divided into five different ranges, which, then in turn, were assigned five different literacy levels:

Level 1 indicates persons with very poor skills, where the individual may, for example, be unable to determine the correct amount of medicine to give a child from information printed on the package.

Level 2 respondents can deal only with material that is simple, clearly laid out, and in which the tasks involved are not too complex. It denotes a weak level of skill, but more hidden than Level 1. It identifies people who can read but test poorly. They may have developed coping skills to manage everyday literacy demands, but their low level of proficiency makes it difficult for them to face novel demands, such as learning new job skills.

Level 3 is considered a suitable minimum for coping with the demands of everyday life and work in a complex, advanced society. It denotes roughly the skill level required for

37 Organisation for Economic Co-operation and Development (OECD) and Statistics Canada, Literacy in the Information Age: Final Report of the International Adult Literacy Survey (2000) at ix [OECD and Statistics Canada, Literacy in the Information Age].

38 Ibid at ix.

39 Ibid.

40 Ibid at ix, $\mathrm{x}$.

41 OECD and Statistics Canada, Literacy, Economy and Society: Results of the First International Adult Literacy Survey (1995) at 14.

42 OECD and Statistics Canada, Literacy in the Information Age, supra note 37 at $\mathrm{x}$.

43 Ibid. 
successful secondary school completion and college entry. Like higher levels, it requires the ability to integrate several sources of information and solve more complex problems. Levels 4 and 5 describe respondents who demonstrate command of higher-order information processing skills. ${ }^{44}$

As part of the IALS, national studies were conducted that measured the proportion of individuals in a given country who were operating at each of these five levels, across three "domains" of literacy: prose, document, and quantitative. In brief, prose literacy is concerned with "the knowledge and skills needed to understand and use information from texts, including editorials, news stories, brochures, and instruction manuals;" document literacy is concerned with "the knowledge and skills required to locate and use information contained in various formats, including job applications, payroll forms, transportation schedules, maps, tables and charts;" and quantitative literacy is concerned with "the knowledge and skills required to apply arithmetic operations, either alone or sequentially, to numbers embedded in printed materials, such as balancing a chequebook, figuring out a tip, completing an order form or determining the amount of interest on a loan from an advertisement." ${ }^{45}$ Canada's national study revealed, for example, the percentage of Canadian adults who were performing at each of the IALS five levels in the document literacy domain (see Figure 1).

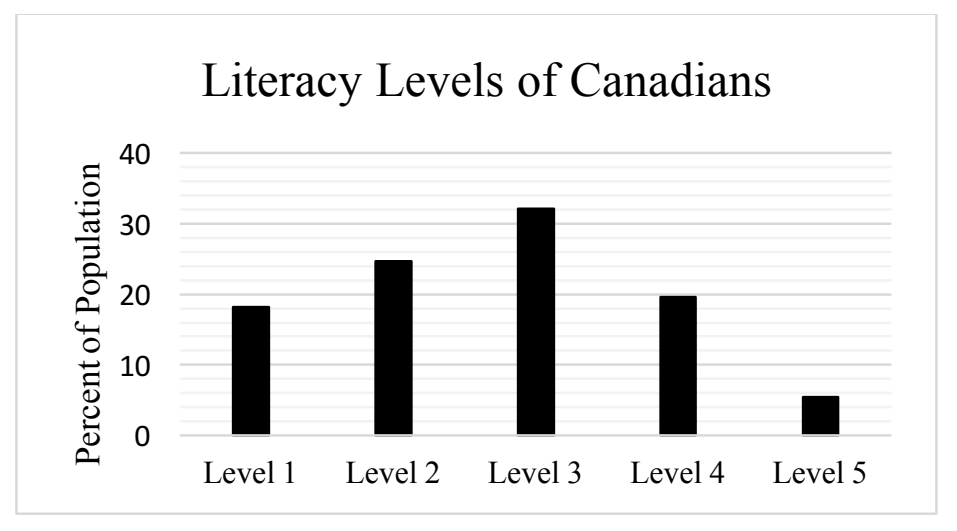

Figure 1: Literacy Levels of Canadians as a Percentage of Population

As noted above, the IALS level assigned to an individual reflects the complexity of the tasks that that individual is able to complete. In general, an individual with a given level of functional literacy will be successful 80 percent of the time at a task at the same level of complexity. ${ }^{46}$ More importantly for the study conducted here, once aggregate functional literacy levels are determined for a population, we can predict the degree to which any given task will be challenging for the population. The above data suggest, for example, that the vast majority of Canadians ( 82 percent) are likely to be able to complete a

44 Ibid at xi.

45 Ibid at $\mathrm{x}$.

46 Evetts \& Gauthier, supra note 1 at 14. 
task rated at level 2 or below (since 82 percent of the population were identified as having functional literacy at level 2 or above).

If one is concerned about the accessibility of documents that the public is interacting with, such as, for example, court forms, the functional literacy approach provides two avenues for intervention to increase the likelihood of success in completing a literacy task. There is, quite obviously, the approach of working with individuals to improve their literacy levels through training and education. Alternatively, one can focus on the task rather than on the individual and work to reduce the complexity of the task by reducing prose, document, and quantitative literacy demands. An intervention at the level of the task, rather than the individual, requires the ability to identify the complexity of a task and, relatedly, the ability to identify strategies to reduce task complexity.

In the 2005 Literacy Task Assessment Guide, Evetts and Gauthier provided a rating tool for assessing task complexity and offered suggestions for reducing the complexity of tasks. ${ }^{47}$ As noted in the introduction, the rating tool measures the difficulty of a task "by analyzing in terms of the type of information (concrete versus abstract), the document complexity (organization and structure), [and] the type of cognitive processing strategies and their processing conditions to determine a profile of the task complexity." 48 This analysis results in a numerical rating being assigned to a task that can then be associated with an estimated IALS level. In other words, a score is given to an individual task that can help us understand what minimum level of literacy an individual would likely need to complete the task. For example, we can look at a task in a court form and determine, for example, if an individual at a level 2 or lower could probably complete this task. A more comprehensive explanation of the rating tool is provided in the fifth part of this article below in the context of discussing the methodology of this study. To our knowledge, the approach reflected in the rating tool has not yet been used to assess court documents.

\section{OUR STUDY}

\section{A. Methodology}

\section{Court Forms Chosen}

The forms assessed in this study involve three different litigation environments in Ontario: Small Claims Court, Family Court, and the Landlord and Tenant Board. The goal in examining several different litigation environments is to provide a broader assessment of literacy requirements and a greater basis for comparison than would be allowed if only one type of proceeding was examined. We chose these three particular environments given the available information indicating that these environments are ones that SRLs are commonly engaged with. ${ }^{49}$ In each of the three areas, the particular

\section{Ibid.}

$48 \quad$ Ibid at 5.

49 See, e g, Macfarlane, supra note 12 (describing the composition of individuals involved in her study as follows: " $60 \%$ of the SRL were family litigants and $31 \%$ were litigants in civil court (13\% in small claims and $18 \%$ in general civil). $4 \%$ were appearing in tribunals (the remainder were unassigned)." With respect to the Landlord and Tenant Board, see David Wiseman, "Research Update: Paralegals, the Cost of Justice and Access to Justice: A Case Study of Residential Tenancy Disputes in Ottawa," online: <http://www.cfcj-fcjc.org/a2jblog/research-update-paralegals- 
forms assessed reflect: (1) the main pieces of paperwork required to initiate proceedings in a specific fictional scenario (as described below); and (2) the guides developed by the government to assist individuals in completing the required paperwork.

In some cases, additional forms - for example, affidavits of service - may be required in order for a litigant to properly initiate his or her case. Moreover, there are additional guides, often published by non-profit legal assistance organizations, that are available to SRLs to assist them in filling out the required forms. Due to concerns with the scope of this study, these additional documents have not been examined. Our focus was solely on the main pieces of paperwork required to initiate proceedings and the guides published by the government to assist the public in filling out each of the forms.

Finally, in "real life," the individual completing the court forms would likely be interacting with additional sources of information that could impact the complexity of the task - for example, an individual might have to look up their postal code on the Canada Post website when filling in address information or look at a receipt to determine how much they should claim for damages. To be sure, the complexity of any ancillary tasks would impact the overall complexity of completing the relevant form. However, because of the nature of this study - a hypothetical analysis of these forms by reviewers - our analysis did not directly incorporate these additional sources of information, which would be part of an actual court proceeding. We did generally consider, however, whether additional sources of information would have to be consulted by a court form user when conducting our task complexity analyses. The particular forms and specific scenarios are set out in the following box.

\section{Small Claims Court}

Scenario: An individual wishes to enforce a term in a contract that requires another individual to pay him or her a fee of less than $\$ 25,000$ (that is, a monetary amount within the jurisdiction of the court).

Court form: Plaintiff's Claim (Form 7A)

Guide: Guide to Making a Claim

\section{Landlord and Tenant Board}

Scenario: A tenant is upset about the behaviour of his or her landlord and wants to pursue remedies against him or her.

Court form: Application about Tenant Rights (Form T2)

Guide: Application about Tenant Rights Instructions 
Family Court

Scenario: An individual seeks a contested divorce, which includes a contested spousal support claim and division of property.

Court forms: Divorce Application (General) (Form 8) and Financial Statement (Property and Support Claims) (Form 13.1)

Guide: Information Before You Start Guide and Starting a Family Case Guide

\section{Process for Evaluating Forms}

In this study, two researchers (both law students) assessed the overall complexity of the tasks contained in the court forms examined using the rating tool. Broadly, using the rating tool involves four steps:

1. identifying the task to be considered;

2. deciding whether the task has the feature of prose, document use, or quantitative task;

3. rating relevant complexity factors; and

4. comparing ratings for each task to typical complexity value ranges, which can then be connected to the IALS level needed to complete the task. ${ }^{50}$

With respect to step 1, in our assessment of the court forms, each field in the document was evaluated as a separate task. As a result, a large number and variety of tasks were evaluated. In total, 282 different tasks were evaluated. These tasks covered a broad range of activities, including, for example, responding to a field that requests "name" or answering, in the case of the Landlord and Tenant Board, "what else do you want the Board to order?"

Regarding step 2, the majority of tasks (70.6 percent) were classified as "Document" tasks, meaning that the tasks required the user to interact with the court forms and potentially other documents, including, for example, the guides or personal documents that the user might have that might contain relevant information (for example, a driver's licence or delivered mail that might contain the user's postal code that they would need for the form). ${ }^{51}$ A much smaller percentage (29.4 percent) of tasks were classified as "quantitative" tasks, meaning that the task required manipulation of numbers including the application of arithmetic functions. ${ }^{52}$ Tasks classified as quantitative (largely restricted to the Family Court Financial Statement) included identifying how much money is being claimed or, in the case of the Financial Statement, such things as calculating and listing "total monthly income from all sources."

Step 3 represents the heart of the complexity analysis and the rating tool provides detailed information about how to rate relevant complexity factors. In short, the complexity rating for a task

Evetts \& Gauthier, supra note 1 at 55.

Ibid at 2.

Ibid at 2. An exception to this statement is the Family Court Financial Statement form, which unsurprisingly, includes a significant number of quantitative tasks. 
involves assessing: (1) the structural complexity of associated materials (or "document complexity"); and (2) the process complexity related to the task that the user is required to complete (or "task complexity"). The sub-factors considered in relation to each of these two assessments include the following.

\section{(a) Document Complexity}

This involves an assessment that considers:

- Structure: how complex is the "list" structure for the document;

- Density: how many labels (that is, headings) are contained in the document? How many pieces of information are requested; and

- Dependency: does the document make reference to information in a related document or as a dependency ? $^{53}$

\section{(b) Task Complexity}

In the case of document tasks, this involves analyzing:

- Type of information requested: a task is assigned a numerical value depending on how concrete or abstract the requested information is (for example, tasks that require individuals to provide reasons or motivations as opposed to simply filling in concrete information, such as a name or an address, are classified as more difficult). ${ }^{54}$

- Type of match required: this analysis is much more complex and requires, among other things, an analysis of which of the following four strategies the user needs to employ: locating, cycling, integrating, or generating. ${ }^{55}$ For example, in the Application about Tenant Rights form, the task of including the landlord's name and address on a form requires that the user "locate" this information from other sources, while the field that asks the user to explain how they came up with the particular rent abatement requested was classified as a "generate" task. An example of a "cycling" task that was found in several forms was the requirement to list the appropriate courthouse for the action. This task would require the user to refer to multiple government websites in order to locate the relevant information. The type of match analysis also takes into account other factors including such things as whether an inference is needed and how many pieces of information need to be included.

- Presence of plausible distractors: The third factor to be considered in assessing the complexity of a document use task requires an evaluation of whether there are any "plausible distractors" in the field's assigned task. As defined by Evetts and Gauthier, a distractor is:

Ibid.

Ibid at 35 .

Ibid at 38-46. 
[a] word, phrase or feature which is similar to the word, phrase or feature being given or requested in questions and directives. If the distractor is for the given information, it will cause the reader to look for the answer in the wrong place; if the distractor is for the requested information, the reader making a correct match on the given word, phrase or feature will be confronted by several possibilities for the requested information - the answer and one or more distractors. ${ }^{56}$

In our study, an example of a plausible distractor was identified with respect to a field that requested a "phone number." Although the intent was for the user to fill in the relevant court's phone number, there is a possibility that the applicant will be confused and believe that they need to fill in their own phone number. For tasks in the court forms that involve interpreting undefined terms such as "representative" or "supporting documents," plausible distractors will exist because an individual may misunderstand what information is being requested.

In the case of quantitative tasks, assessing task complexity involves analyzing:

- Type of operation: the type of operation "refers to the actual arithmetic operation that must be carried out as part of the literacy task. ${ }^{, 57}$ As noted by Evetts and Gauthier, "[i]n general, addition is easier than subtraction; multiplication is easier than division ... [and] [s]ingle arithmetic operations are always easier than combinations of more than one operation." ${ }^{58}$

- Specificity of operation: the specificity of operation refers to "the process of setting up an arithmetic operation according to the parameters set forth in the question or directive." When rating the specificity of an operation, one is required to look at such things as whether the numbers to be used are obvious and whether the numbers "appear in row or column format rather than in a random arrangement (as for example in a prose paragraph). ${ }^{" 60}$ An example of a quantitative task that was evaluated in this study was the field on the Financial Statement form that requires an individual to list the unemployment benefits that they received on a monthly basis. Assuming that an individual has received such benefits on a biweekly basis, filling in this field is a somewhat complex task as it requires an inference that multiplication is necessary and also the use of numbers that are contained in another document.

- Presence of plausible distractors: see the explanation above.

\footnotetext{
Ibid at 124 .

Ibid at 51.

Ibid.

Ibid at 52 .

Ibid.
} 
Under this framework, the complexity score for a task is arrived at through the sum of (1) the document complexity rating and (2) the task complexity rating. Both of these ratings are in turn arrived at by adding up the scores given to each of the relevant sub-factors listed above.

Step 4 then involves comparing ratings for each task to typical complexity value ranges, which can then be connected to the IALS level needed to complete the task. According to Evetts and Gauthier, the overall complexity scores given to a task typically range from zero to sixteen. ${ }^{61}$ The authors further identify the following ranges of overall task complexity scores as corresponding to each of the five IALS levels (see Figure 2). ${ }^{62}$

\begin{tabular}{|l|l|}
\hline Overall Task Complexity Score & IALS Level \\
\hline $0-6$ & 1 \\
\hline $7-8$ & 2 \\
\hline $9-10$ & 3 \\
\hline $11-13$ & 4 \\
\hline $14-16$ & 5 \\
\hline
\end{tabular}

Figure 2: Correspondence between Overall Task Complexity Scores and IALS Levels

Thus, each task can be assigned an IALS rating by comparing the overall task complexity score to these ranges. Assignment of an IALS level to a task allows us to "backwards map" to determine the functional literacy level required to successfully complete the task. A task of level 2 complexity, for example, will be successfully completed 80 percent of the time by individuals whose functional literacy is assessed at level $2 .^{63}$

\section{B. Study Results}

\section{Document Complexity}

As discussed above, the complexity of the individual tasks on each form was, in part, determined by the complexity of the documents associated with that task - the form in which the task was contained and the associated guide. As noted above, the assessment of document complexity examines a variety of factors relating to structure, density, and dependency. Using the criteria and ratings provided in the guide, the following document complexity evaluations were given to the court documents and guides:

\section{Small Claims Court \\ a. Plaintiff's Claim: very low complexity \\ b. Small Claims Guide: high complexity}

2. Landlord and Tenant Board

a. Application about Tenant Rights: low complexity

\footnotetext{
${ }^{61}$ Ibid at 65. Evetts and Gauthier acknowledge that scores higher than sixteen are also possible, reflecting an extremely high level of complexity.

62 Ibid at 65.

63 Ibid at 14.
} 

3. Family Court
a. Divorce Application: low complexity
b. Financial Statement: very high complexity
c. Information Before You Start Guide: low complexity
d. Starting a Family Case Guide: moderate complexity
e. Financial Statements Guide: very low complexity

b. Application about Tenant Rights Instructions: moderate complexity

Documents with low or very low complexity are not considered to influence task complexity, but documents with higher complexity increase the complexity of the associated task. Among the four forms considered (Plaintiff's Claim, Application about Tenant Rights, Divorce Application, and Financial Statement), only the last - the Financial Statement - is complex enough to influence task complexity, and among the five guides, two are at low or very low complexity, while the remaining three (the Small Claims Guide, the Application about Tenant Rights instructions, and the Starting a Family Case Guide) are complex enough to affect the complexity of associated tasks. For the full and detailed breakdown of the document analysis conducted, please see Appendix A.

One important observation from the above results is that the guides intended to assist individuals in completing court forms were, in many cases, more complex at a document level than the actual forms themselves. This observation echoes the conclusion reached in the Court Guides Assessment project contained in the Macfarlane report, which, using different criteria and looking at a different set of forms, found that the court guides contained a number of features that would likely create challenges for SRLs. ${ }^{64}$ The issues highlighted in the Court Guides Assessment project included unclear grammatical expression, use of technical terms, vague instructions, and overly high reading levels. ${ }^{65}$ The different evaluative criteria used in this study resulted in the identification of different document-level problems. The major reason that the court guides examined in this study yielded high ratings of document-level complexity was because they were quite dense - that is, they contained a large number of labels or items of information. For example, the Small Claims Guide contained sixty-six labels (including all headings with sub-items) and 249 items (including pieces of information such as paragraphs or bullet points in the Small Claims Guide).

\section{Task Complexity Ratings}

As noted above, the ratings tool was used to evaluate the complexity of 282 tasks contained in the four court forms examined: (1) Plaintiff's Claim (small claims form) (36 tasks); (2) Application about Tenant Rights (Form T2) (Landlord and Tenant Board) (68 tasks); (3) Divorce Application (Family Court) (36 tasks); and (4) Financial Statement (Family Court) (142 tasks). The assessment of each task involved engaging in the four steps discussed in the Methodology section above. This evaluation ultimately produced over 100 pages of analysis. To provide some sense of what the analysis of

\footnotetext{
64 Macfarlane, supra note 12 at 65-66. Three court guides from three different provinces (Alberta, British Columbia, and Ontario) were assessed as part of the Court Guides Assessment project. Only the Ontario guide - the Ontario Small Claims Guide - was also assessed in this study.

65

Ibid.
} 
individual tasks looked like, three examples are provided in Appendix B. Details regarding the estimated IALS level for each of the 282 tasks on the four court forms are provided in Appendix C.

Slightly over half of the tasks (56.7 percent; 160 of 282) were identified as level 2 or below; this proportion varied from a high of 79.4 percent for the Application about Tenant Rights (Form T2) to a low of 42.3 percent for the Family Court Financial Statement. Slightly over one quarter of tasks (28.4 percent; 80 of 282 tasks; low of 10.3 percent for the Application about Tenant Rights to a high of 39.4 percent for the Family Court Financial Statement) were identified as level 4 or 5.

As discussed above, the complexity of guides that are intended to help with form completion can (if complexity of these documents is high enough) influence the complexity of associated tasks. It is of value, therefore, to examine task complexity if the complexity of the guides was reduced, either by rewriting or through the use of electronic forms that incorporate tailored, just-in-time information from the guides. These types of changes, which would definitely assist SRLs to read and understand court forms, would reduce, but not eliminate, the issue of task complexity. If task complexity is assessed without any contribution from the complexity of guides, the proportion of tasks at level 1 or level 2 increases to 57.4 percent (162 of 282 tasks), but 26.9 percent of tasks (76 of 282) remain at level 4 or level 5. Thus, if we are interested in improving the ability of SRLs to complete required court forms, we must address the complexity of both form and supporting documents, and we must reduce the complexity of tasks involved in the form completion.

As indicated above, approximately 80 percent of Canadians will be able to complete successfully (the majority of times) a task of complexity level 2 or below. Thus, it seems reasonable to identify level 2 or below as an "appropriate" level of task complexity. The four forms considered differ greatly in the proportion of tasks that fall within this range. While a large majority of the tasks associated with the Plaintiff's Claim form and the Application about Tenant Rights form have an estimated IALS level of two or below (75 percent and 79.4 percent, respectively) and very few tasks assessed at levels 4 or 5 (11.1 percent and 10.3 percent, respectively), the family law court forms (Financial Statement and Divorce Application) have much lower proportion of level 1 or 2 tasks (42.3 percent and 52.8 percent, respectively) and a much higher proportion of level 4 or 5 tasks (39.4 percent and 36.1 percent, respectively).

It should be noted that even if the majority of tasks on a form are rated at complexity level of 2 or below, if the most critical tasks require level 4 or 5 to be completed, the form may, in effect, still be inaccessible to many individuals. In the context of the Plaintiff's Claim form, for example, if the individual is not able to complete the one field that requires him or her to effectively describe the nature of his or her claim (that is, one of the more complex tasks on the form), the form will not perform its function.

Information about what, specifically, made aspects of the court forms complex can be obtained from an analysis of each of the four specific factors considered in the individual task complexity analyses. As noted above, in the case of document tasks, these factors are: (1) type of information; (2) type of match; (3) plausible distractors; and (4) document complexity. The four factors considered when reviewing quantitative tasks are: (1) type of operation; (2) specificity of operation; (3) plausible distractors; and (4) document complexity. 


\section{Analysis of Document Tasks}

Of the 282 tasks, 199 (70.6 percent) were classified as document tasks, including the vast majority of tasks on the Plaintiff's Claim (97.2 percent) and the Application about Tenant Rights (89.7 percent) and all tasks on the Divorce Application. In contrast, only 47.2 percent of the tasks on the Financial Statement form were classified as document tasks. Overall, document tasks were of relatively low complexity: 65.8 percent of these tasks were identified as level 1 or 2 . At the same time, roughly one fifth of these tasks (20.1 percent) were classified as level 4 or 5 and, thus, well beyond the capacity of most Canadians. An understanding of what made some of these document tasks complex can be gained through trends seen with respect to each of the four task complexity factors that were examined.

First, with respect to the type of information factor for these tasks, the vast majority of tasks were assigned low ratings because they involved providing more concrete information like names, dates, and addresses or involved "yes or no" questions. For example, one field on the Divorce Application asks the user: "have the parties arbitrated or agreed to arbitrate any matter involved in this case?" There were, however, more complex requests for information involving the user having to indicate a goal, leading to a higher rating on this factor (for example, a field on the Divorce Application that asks for "claims under the Divorce Act") or having to provide an explanation leading to an even higher complexity rating (for example, the field on the Divorce Application that asks the user to "give details of the order that you want the court to make").

Second, many of the document tasks that were ultimately rated at a level 3 or higher required the user to engage in a complex type of match exercise. There were several different kinds of "type of match" complexity observed, including tasks that required the user to "generate" information that requires expert legal knowledge or complex informational responses. For example, one field of the Divorce Application form requests that the user "[g]ive details of the order that you want the court to make." Similarly, a field on the Plaintiff's Claim form asks the user to "explain what happened, including where and when. Then explain how much money you are claiming or what goods you want returned." These type of tasks are highly complex in that they require the user to "generate" information (rather than, for example, simply "locating" information such as the current date) based on his or her personalized circumstances, requiring high inference, expert legal knowledge of what type of orders can be made, and an ability to explain this effectively. With respect to the example from the Divorce Application, no guidance is provided in the associated court guide regarding filling in this field. Similar issues arise in relation to fields that require the user to clarify what specific claims are being requested (take, for example, the field on the Divorce Application that requires the user to indicate if the claim includes a request for support but not "a claim for property or exclusive possession of the matrimonial home and its contents."). Another example of a field that would require expert legal knowledge, from the Application about Tenant Rights, is the field that requests the user to identify any accommodations under the Ontario Human Rights Code that they might need. ${ }^{66}$ Determining what types of circumstances are considered for accommodation is a difficult task. One example is given on the form (sign language interpreter), but there are countless other potential accommodations. Similarly, there is a field on the Financial Statement form that requires the user to state the market value of his or her furniture and other household items.

66 Human Rights Code, RSO 1990, c H.19. 
Itemizing belongings is a substantial task. Having to provide estimates of value for each item is even more complicated. Moreover, finding an estimated market value of furniture and household items requires expert knowledge on the topic. This information may change with the fluctuation of the markets and require significant research.

A second kind of "type of match" complexity observed was the task of inferring the meaning of technical legal terms or making other high level inferences. For example, as mentioned above, a field on the Divorce Application asks the user: "[h]ave the parties arbitrated or agreed to arbitrate any matter involved in this case?" Among other things, this task requires an inference to determine what is meant by "arbitration," and an individual may need to look this legal term up. The proper definition may be difficult to find or understand. This example demonstrates the value of the fact that the ratings tool takes into account multiple factors when determining total task complexity. Although this particular field scored low on type of information complexity, its overall complexity ends up being high due to the fact that its type of match complexity is high. Another example is a field on the Application about Tenant Rights asks the user "[w] $[\mathrm{w}$ hat else do you want the Board to order?" and provides the chance to list remedies beyond those otherwise specifically listed in the application. However, the guide does not explain what other remedies the tribunal can order other than stating that " $\mathrm{t}]$ he LTB can make any other order that it considers appropriate," leaving the user to infer what orders he or she can seek. Other examples of fields which would require the user to interpret a legal or otherwise technical term, include requests for the user to:

- indicate if they are claiming "pre-judgment interest" and from what date (Plaintiff's Claim);

- fill in "Plaintiff no. 1" (Plaintiff's Claim);

- indicate if the reason that they are applying to the tribunal for remedies is because his or her landlord, landlord's agent, or superintendent entered their rental unit "illegally" or "substantially interfered" with their "reasonable enjoyment of the rental unit or complex or with the reasonable enjoyment of a member of [their] household" (Application about Tenant Rights);

- provide the "yearly market value" of any "non-cash benefits" provided by his or her employer or business (Financial Statement); and

- provide "valuation date" (Financial Statement).

A third kind of "type of match" complexity observed is the "cycle" between several different information sources. For example, the Divorce Application, the Financial Statement, and the Plaintiff's Claim forms all ask the user to fill in information about the appropriate court. In order to complete these fields, the user will first have to cycle (that is, refer to) the guides to determine the correct municipality in which he or she should be applying; then he or she will have to search the Ontario Attorney General website to find a link to "court address," and, after doing so, the user will then finally have to engage with an interactive map where he or she will select the relevant municipality and the type of court address desired. Another example of cycling that is required is in respect to fields that require the user to explain how they calculated damages (for example, the Application about Tenant Rights asks with respect to certain remedies: "Please explain: How did you calculate the expenses?"). To perform this 
task, an individual would have to move between the form, sources of information about expenses incurred (for example, receipts), and, potentially, a working document in which they outline the calculations made to arrive at their total expenses. Further, the Financial Statement form requires the user to list what documents he or she is attaching as proof of income over the past three years (and, thus, requires the user to cycle through relevant tax or other income documents and review dates to determine what should be attached).

Third, a number of plausible distractors were also identified as increasing complexity with respect to document tasks, including broad requests for information that fail to specify what type of information is relevant, risking that important information could be left out. For example, one field in the Divorce Application asks: "have the parties made a written agreement dealing with any matter involved in this case?" Notably, the associated court guides do not provide a definition of "agreement" in the context of this field. By way of another example, the Financial Statement form has a field that requires the user to list what documents he or she is attaching as proof of income over the past three years. However, it is not clear if income other than from employment, such as disability benefits, interest, rent, or other means, is meant to have supporting documentation submitted as well. Another field on the Financial Statement form requires the user to list "other special items" that they own, and it is possible that valuables may be incorrectly added or left out of this category due to the ambiguous nature of the term "special items."

A second plausible distractor is the use of unclear terms/unclear requests for information. For example, the Divorce Application has a blank for "court file number," but it is unclear that the user should leave this section blank. Similarly, the Plaintiff's Claim form has a blank for "claim no.," and it is again unclear that this term refers to the court file number assigned by the court, and additional confusion is added by the fact that the associated guide refers to "court file number," while the form uses the term "claim no." to refer to the same thing. Other examples of the use of unclear terms possibly leading to distraction is the request in the Plaintiff's Claim form for an individual's "second name" or the reference in the Application about Tenant Rights to "out of pocket expenses." Relatedly, in some cases, abbreviations were used - for example, "no." for "number" and "prov." for "province" - which could potentially lead to unnecessary confusion or the need to "cycle" to another source of information to look up the abbreviation.

Fourth, with respect to document-level complexity, the Divorce Application, the Plaintiff's Claim, and the Application about Tenant Rights were themselves rated to be of low complexity, and, as such, no additional scores for complexity were added on the basis of the document-level complexity of the forms themselves. However, one of the associated guides for filling in the Divorce Application (Starting a Family Case guide) and the guides associated with the Plaintiff's Claim form and the Application about Tenant Rights form had higher document-level complexity ratings (see Appendix A for more information), increasing the complexity for the fields that required that the user refer to the guide. In contrast, the Financial Statement form itself is a highly complex document, which significantly affects how difficult it is to complete the form and, according to the rating tool, resulted in additional points of complexity being assigned to each task in that form.

With respect to guide use, it should also be noted that the Divorce Application, the Financial Statement form, and the Plaintiff's Claim do not reference their associated court guides directly - this was observed to be a significant flaw. It was also observed that, as a general matter, there was no simple 
way to cross-reference which section of the guides explains how to fill out the respective parts of the forms. With respect to several fields, it was noted that neither guide provided any guidance or explanation for filling out the field, which made completing the field challenging. In some cases, the guide lacked obvious information that would be highly useful. For example, the term "valuation date" is used throughout the Financial Statement form but is not defined anywhere in the guides or the form itself.

\section{Analysis of Quantitative Tasks}

The remaining tasks analyzed (eighty-three tasks, or 29.4 percent) were quantitative tasks. The vast majority of the quantitative tasks were found on the Financial Statement form (52.8 percent of the tasks on this form were quantitative tasks, compared to 0 percent on the Divorce Application, 2.8 percent on the Plaintiff's Claim, and 10.3 percent of tasks on the Application about Tenant Rights form). Just over one third of these tasks (34.9 percent) were classified as level 1 or 2 , while slightly under one half (48.2 percent) of these tasks were classified as level 4 or 5 . Thus, in general, quantitative tasks included on these forms present a higher degree of challenge.

As per the ratings tool criteria, the rank given to the difficulty of quantitative tasks varied depending on what type of operation was required. One type of quantitative task that appeared on both the Plaintiff's Claim form and the Application about Tenant Rights was a requirement for the user to specify the amount of damages that he or she was claiming. The difficulty of the operation of this task will vary depending on the claimant's circumstances. For example, does calculating damages in the case involve adding up a few expenses or would multiplication be necessary, as it would be if losses over several months were claimed?

There was more variety in the complexity observed for the quantitative tasks in the Financial Statement form. One third (twenty-five out of seventy-five) of the quantitative tasks in this form involved addition and were, therefore, given a low complexity rating. An example of this type of task would be the field that requires the user to provide his or her gross income from all sources. There were relatively few tasks of more moderate complexity, requiring subtraction (three fields), multiplication (nine fields), or division (three fields). However, there were a significant number of tasks (thirty-five) that were assigned the highest complexity rating for the type of operation because they involved "combined" operations. An example of this type of task would be the field that asked the user to indicate "Child Tax Benefits or Tax Rebates (e.g., GST)." A user completing this field may have to engage in a combination of mathematical processes because, if an individual receives multiple tax benefits, they must be added together to find the monthly total, and, assuming that one of those is the GST tax rebate, which is paid quarterly, the rate must be converted to monthly (that is, divided) before adding it to the Child Tax Benefits.

For the quantitative tasks, there was also complexity observed in relation to the specificity of operation factor. With respect to this factor, additional complexity was assigned to tasks in several instances due to the fact that it was necessary for the user to infer what type of mathematical operation they would need to engage in. For example, one field in the Financial Statement form requires the user to list total monthly income from commissions, tips, and bonuses, and, although an example is provided in the associated guide regarding how one might calculate a weekly rate into a monthly one, there is no further information on how one might calculate this monthly income if the amounts vary each month. 
Similarly, in several cases, it was necessary for the user to infer what numerical information would be relevant. For example, with respect to the field in the Financial Statement form that requires the user to fill in "Child Tax Benefits or Tax Rebates (e.g., GST)," there is no list of what types of benefits should be included under Child Tax Benefits or tax rebates, other than GST. Therefore, it must be inferred what documents will provide the relevant information. Finally, in a number of instances, complexity was observed because the requested response would likely require the individual to engage in a search of multiple receipts, invoices, or documents (for example, a field on the Financial Statement form that would require the user to detail how much money they spend a month on vacations).

The issue of plausible distractors is also relevant for quantitative tasks, and there were several identified in the Financial Statement that contributed to tasks being rated at a higher level of complexity. One example is a field that requests "Self-employment income (Monthly amount before expenses: $\$$

$\$$ _." The field in brackets is somewhat confusing as it seems to imply that the amount before expenses is to be entered in the brackets, but it does not clarify what should be entered in the next field on the same line. This could result in the wrong amount being entered. Another example is the field requesting that the user list "education" expenses. The request to specify the expenses for education is vague and does not state which details are relevant. There is a possibility that important information will be left out since this is not clear.

Finally, with respect to document complexity for the quantitative tasks, as noted above, the Plaintiff's Claim and the Application about Tenant Rights were themselves rated to be of low complexity. As such, no additional scores for complexity were added to quantitative tasks on the basis of their complexity. However, some additional scores were added for those tasks that required more complex associated court guides to answer. For quantitative tasks in the Financial Statement form, additional complexity points were added since the form itself is a highly complex document.

\section{LIMITATIONS AND FUTURE RESEARCH}

As reflected in the previous section, using the functional literacy approach contained in the rating tool can usefully highlight specific aspects of court form tasks that may make them complicated for nonlegally trained individuals to complete. In considering this study's results, however, it is important to acknowledge several limitations. First, it is important to acknowledge that, although the rating tool assigns a numerical rating to the complexity of tasks, this quantitative result is the result of how the reviewer chooses to describe the tasks at issue and that such choices involve a degree of subjectivity. Different reviewers may assign different ratings to tasks, although one would expect that the results would be roughly comparable if individuals are using the rating tool correctly. Second, it should be noted that the reviewers in this case - two law students - have some legal training and that this may have influenced their perceptions of the tasks contained in the court forms, notwithstanding the fact that they aimed to put themselves in the position of a non-legally trained individual in assessing the forms. Finally, as discussed in the introduction, since the IALS study and the rating tool were published, there have been additional studies measuring the literacy level of Canadians and changes in the frameworks used to measure the literacy level of individuals. However, there have been no other tools that we are 
aware of that have been developed to assess the literacy level requirements of documents in relation to these new literacy measurements. ${ }^{67}$

The limitations discussed in the previous paragraph would be significant if the intent of this study was to provide definitive and specific literacy measurements. Fortunately, the intent here is more modest and involves using the rating tool as a means to: (1) identify broad and recurring issues with the court forms examined; and (2) suggest ways to reduce complexity. Completing these two tasks involves general assessments of relative complexity that remain largely undisturbed whether one is, for example, using the IALS framework or more recent frameworks to assess literacy. Moreover, while the fact that some subjectivity and artificiality is built into the process warrants some caution in interpreting results, these constraints do not, in our view, detract from the usefulness of this study as one means to understand some of the major reasons that court forms are complex. Finally, further empirical work is in progress to establish whether the challenges identified in this analysis are corroborated in the experience of untrained individuals attempting to complete these court forms.

\section{CONCLUSION AND RECOMMENDATIONS}

The results of this study provide some insight as to why tasks contained in court forms may be challenging for SRLs to complete. Although envisioning comprehensive solutions to the challenges identified is beyond the scope of this study, this section of the article contains some preliminary thoughts regarding remediating barriers that SRLs may face in using court forms.

First, it is apparent that some of the challenges identified above can be addressed through document redesign. For example, it would be quite easy to ensure that court forms contain an explicit reference to any associated guide so that the user is aware that he or she can consult the instructions contained therein. Likewise, it would be simple to clarify that blanks on court forms relating to the "court file number" should not be filled in by the user but, rather, will be filled in by the court - the form designers could address this issue by labeling these types of fields for "office use only" or "to be filled in by court." Finally, form designers could also eliminate confusion by refraining from using abbreviations for words. The space required to write, for example, "number" instead of "no.," would be insignificant, and providing the full word would result in the field being clearer to users.

Second, the reality that many of the court guides are complex documents containing a significant amount of information that is not always straightforwardly organized suggests that there may also be value in using "dynamic" electronic forms that integrate the court forms and guides and that provide tailored and "just-in-time" information to users. Indeed, there appears to be a trend by courts towards pursuing this type of technological solution to increase access to justice for members of the public. For example, e-filing is now allowed for claims in Ontario's Small Claims Court, permitting users to electronically file court forms either by uploading completed paper forms or by using a "filing wizard," which is stated to be designed to walk users through the filing process in order to ensure that they submit

67 Statistics Canada, Skills in Canada, supra note 4 at 16; Statistics Canada, Building on Our Competencies, supra note 4. 
all necessary information to the court. ${ }^{68}$ Similarly, the Landlord and Tenant Board also now permits efiling for certain applications, including the Application about Tenant Rights that was reviewed in this study. ${ }^{69}$ This e-filing process also purports to guide users through the application process in a step-bystep fashion. ${ }^{70}$ In addition to these government-provided resources, a private third party tool called "Small Claims Wizard" is currently under development that aims to provide a "step-by-step" interview to easily guide users through the Small Claims Court process and offer commentary that will provide "useful insights" specific to an individual's claim. ${ }^{71}$

More ambitiously, British Columbia has recently launched the Civil Resolution Tribunal (CRT), which is self-described as "Canada's first online tribunal." provide the public "with plain language legal information and, when fully implemented, a range of dispute resolution tools including negotiation, facilitation, and adjudication.," ${ }^{, 3}$ In the United States, A2J Author is an online tool that enables the development of "guided interviews," which "take complex legal information from legal forms and present it in a straightforward way to self-represented litigants ... allowing them to easily complete and print court documents that are ready to be filed with the court system." ${ }^{74}$ Although evaluating such tools is beyond the scope of this study, it would appear that they hold promise in that they all provide more tailored guidance to users when completing court forms. Their ultimate value, of course, will depend on the appropriate design and, at the very least, not transplanting problems from paper-based forms to the electronic environment. ${ }^{75}$ For example, the use of abbreviations or unexplained technical terms will be just as much of a problem in a paper-based environment as in an electronic one. Using electronic forms also raises issues of digital literacy and Internet access that must be considered.

Third, the observation in the section above that a number of the court forms require the user to complete tasks that involve generating information that necessitates expert legal knowledge suggests that there are some barriers that SRLs face that cannot be dealt with by form redesign or a move to an interactive digital environment. In some cases, specific and detailed legal knowledge would appear to be essential in order to optimally complete forms. In particular, the results of this study suggest that the family law court forms will be very challenging for many members of the public to complete without legal advice or other expert assistance. Moreover, given the complexity of the issues involved in family

68 Attorney General of Ontario, Small Claims Court E-filing Service User Guide, online:

$<$ https://www.attorneygeneral.jus.gov.on.ca/english/courts/scc/e-filing/small_claims_e-filing_user_guide.html $>$.

69 Social Justice Tribunals Ontario, "LTD e-file," online: <http://www.sjto.gov.on.ca/ltb/e-file/>.

70 Ibid.

71 Small Claims Wizard, online: $<$ http://www.smallclaimswizard.com/\#about>.

72 Civil Resolution Tribunal, “CRT Overview," online $<$ https://www.civilresolutionbc.ca $>$.

73 Ibid.

74 A2J Author, online: <http://www.a2jauthor.org/>. A2J Author is also used in some legal clinics in Canada. For example, fifteen community legal clinics in Ontario now use A2J Author to facilitate a guided interview for individuals denied disability benefits. Community Legal Clinic, "New ODSP Denial Intake Interview Release," $<$ http://www.communitylegalclinic.ca/newsdetail.aspx?ntID=1\&pID=92>.

75 For a broader discussion of the utility of legal self-help resources, see Merran Lawler, Jeff Gibbings, and Michael Robertson, "Opportunities in the Provision of Self-Help Legal Resources to Citizens in Need" (2012) 30:1 Windsor YB Access Just 185. 
law matters, it would appear to be difficult to modify these forms such that expertise would no longer be a huge advantage in form completion. In view of this reality, optimal solutions in the family law context for increasing access to justice of SRLs may require innovative legal service delivery models, such as unbundled legal services or coaching, wherein an individual can receive some expert guidance in respect of a court proceeding without incurring the costs that would be associated with retaining a lawyer to provide full representation for a case. 
Appendix A: Document Level Complexity

Small Claims: Plaintiff's Claim

\begin{tabular}{|l|l|l|}
\hline Document complexity elements & Evaluation & Comments \\
\hline Plaintiff Claim Form & Score: 2 & $\begin{array}{l}\text { Combined list is the highest level of complexity in the } \\
\text { claims form. }\end{array}$ \\
\hline Document structure & Score: 1 & $\begin{array}{l}8 \text { labels, which includes all questions or headings with } \\
\text { sub-items. }\end{array}$ \\
\hline Number of labels & $\begin{array}{l}57 \text { items, which includes fields that can be filled in and } \\
\text { pieces of information in the form instructions. }\end{array}$ \\
\hline Number of items & Score: 1 & One must depend on an outside resource, the claims guide. \\
\hline Dependency & Score: 1 & $\begin{array}{l}\text { Combined list is the highest level of complexity in the } \\
\text { claims guide. }\end{array}$ \\
\hline Total = 5 (very low complexity) & 66 labels, which includes all headings with sub-items. \\
\hline Small Claims Guide & Score: 2 & $\begin{array}{l}\text { 249 items, which includes pieces of information such as } \\
\text { paragraphs or bullet points in the claims guide. }\end{array}$ \\
\hline Document structure & Score: 5 & One must depend on an outside resource, the claims form. \\
\hline Number of labels & Score: 5 \\
\hline Number of items & Score: 1 & \\
\hline Dependency &
\end{tabular}

Landlord and Tenant: Application about Tenant Rights (Form T2)

\begin{tabular}{|c|c|c|}
\hline Document complexity elements & Evaluation & Comments \\
\hline \multicolumn{3}{|l|}{ Application about Tenant Rights } \\
\hline Document structure & Score: 2 & $\begin{array}{l}\text { Combined list is the highest level of complexity in the } \\
\text { application form. }\end{array}$ \\
\hline Number of labels & Score: 2 & $\begin{array}{l}24 \text { labels, which includes all questions or headings with } \\
\text { sub-items. }\end{array}$ \\
\hline Number of items & Score: 2 & $\begin{array}{l}122 \text { items, which includes fields that can be filled in and } \\
\text { pieces of information in the form's instructions. }\end{array}$ \\
\hline Dependency & Score: 1 & $\begin{array}{l}\text { One must depend on an outside resource, the application } \\
\text { form's instructions. }\end{array}$ \\
\hline \multicolumn{3}{|l|}{ Total $=7$ (low complexity) } \\
\hline \multicolumn{3}{|c|}{ Application about Tenant Rights Instructions } \\
\hline Document structure & Score: 2 & $\begin{array}{l}\text { Combined list is the highest level of complexity in the } \\
\text { application form's Instructions. }\end{array}$ \\
\hline Number of labels & Score: 5 & 52 labels, which includes all headings with sub-items. \\
\hline Number of items & Score: 2 & $\begin{array}{l}89 \text { items, which includes pieces of information such as } \\
\text { paragraphs or bullet points in the instructions. }\end{array}$ \\
\hline
\end{tabular}




\begin{tabular}{|l|l|l|}
\hline Dependency & Score: 1 & $\begin{array}{l}\text { One must depend on an outside resource, the application } \\
\text { form. }\end{array}$ \\
\hline Total $=10$ (moderate complexity) \\
\hline
\end{tabular}

\section{Family: Divorce Application and Financial Statement}

\begin{tabular}{|c|c|c|}
\hline Document complexity elements & Evaluation & Comments \\
\hline \multicolumn{3}{|l|}{ Divorce Application (Form 8) } \\
\hline Document structure & Score: 2 & $\begin{array}{l}\text { Combined list is the highest level of complexity in the } \\
\text { Divorce Application. }\end{array}$ \\
\hline Number of labels & Score: 3 & $\begin{array}{l}28 \text { labels, which includes all questions or headings with sub- } \\
\text { items. }\end{array}$ \\
\hline Number of items & Score: 2 & $\begin{array}{l}92 \text { items, which includes fields that can be filled in and } \\
\text { pieces of information in the form instructions. }\end{array}$ \\
\hline Dependency & Score: 1 & $\begin{array}{l}\text { One must depend on an outside resource, the Information } \\
\text { Before You Start Guide. }\end{array}$ \\
\hline \multicolumn{3}{|l|}{ Total $=8$ (low complexity) } \\
\hline \multicolumn{3}{|c|}{ Information Before You Start Guide } \\
\hline Document structure & Score: 2 & $\begin{array}{l}\text { Combined list is the highest level of complexity in the IBYS } \\
\text { Guide. }\end{array}$ \\
\hline Number of labels & Score: 2 & 22 labels, which includes all headings with sub-items. \\
\hline Number of items & Score: 2 & $\begin{array}{l}98 \text { items, which includes pieces of information such as } \\
\text { paragraphs or bullet points in the Information Before You } \\
\text { Start Guide. }\end{array}$ \\
\hline Dependency & Score: 1 & $\begin{array}{l}\text { One must depend on an outside resource, the Divorce } \\
\text { Application. }\end{array}$ \\
\hline \multicolumn{3}{|l|}{ Total $=7$ (low complexity) } \\
\hline \multicolumn{3}{|l|}{ Starting a Family Case Guide } \\
\hline Document structure & Score: 2 & $\begin{array}{l}\text { Combined list is the highest level of complexity in the } \\
\text { Starting a Family Case Guide. }\end{array}$ \\
\hline Number of labels & Score: 4 & 37 labels, which includes all headings with sub-items. \\
\hline Number of items & Score: 2 & $\begin{array}{l}100 \text { items, which includes pieces of information such as } \\
\text { paragraphs or bullet points in the Starting a Family Case } \\
\text { Guide. }\end{array}$ \\
\hline Dependency & Score: 1 & $\begin{array}{l}\text { One must depend on an outside resource, the Divorce } \\
\text { Application. }\end{array}$ \\
\hline
\end{tabular}




\begin{tabular}{|c|c|c|}
\hline \multicolumn{3}{|c|}{ Financial Statement (Form 13.1) } \\
\hline Document structure & Score: 4 & $\begin{array}{l}\text { Nested list is the highest level of complexity in the Financial } \\
\text { Statement. }\end{array}$ \\
\hline Number of labels & Score: 5 & $\begin{array}{l}143 \text { labels, which includes all questions or headings with sub- } \\
\text { items. }\end{array}$ \\
\hline Number of items & Score: 5 & $\begin{array}{l}257 \text { items, which includes fields that can be filled in and } \\
\text { pieces of information in the form's instructions. }\end{array}$ \\
\hline Dependency & Score: 1 & $\begin{array}{l}\text { One must depend on outside resources, the guides listed } \\
\text { below. }\end{array}$ \\
\hline \multicolumn{3}{|c|}{ Total $=15$ (very high complexity) } \\
\hline \multicolumn{3}{|c|}{ Financial Statements Guide } \\
\hline Document structure & Score: 2 & $\begin{array}{l}\text { Combined list is the highest level of complexity in the } \\
\text { Financial Statements Guide. }\end{array}$ \\
\hline Number of labels & Score: 1 & 12 labels, which includes all headings with sub-items. \\
\hline Number of items & Score: 1 & $\begin{array}{l}24 \text { items, which includes pieces of information such as } \\
\text { paragraphs or bullet points in the Starting a Family Case } \\
\text { Guide. }\end{array}$ \\
\hline Dependency & Score: 1 & $\begin{array}{l}\text { One must depend on an outside resource, the Financial } \\
\text { Statement. }\end{array}$ \\
\hline
\end{tabular}

Appendix B: Examples of Individual Task Complexity Analyses Example 1 (simple task)

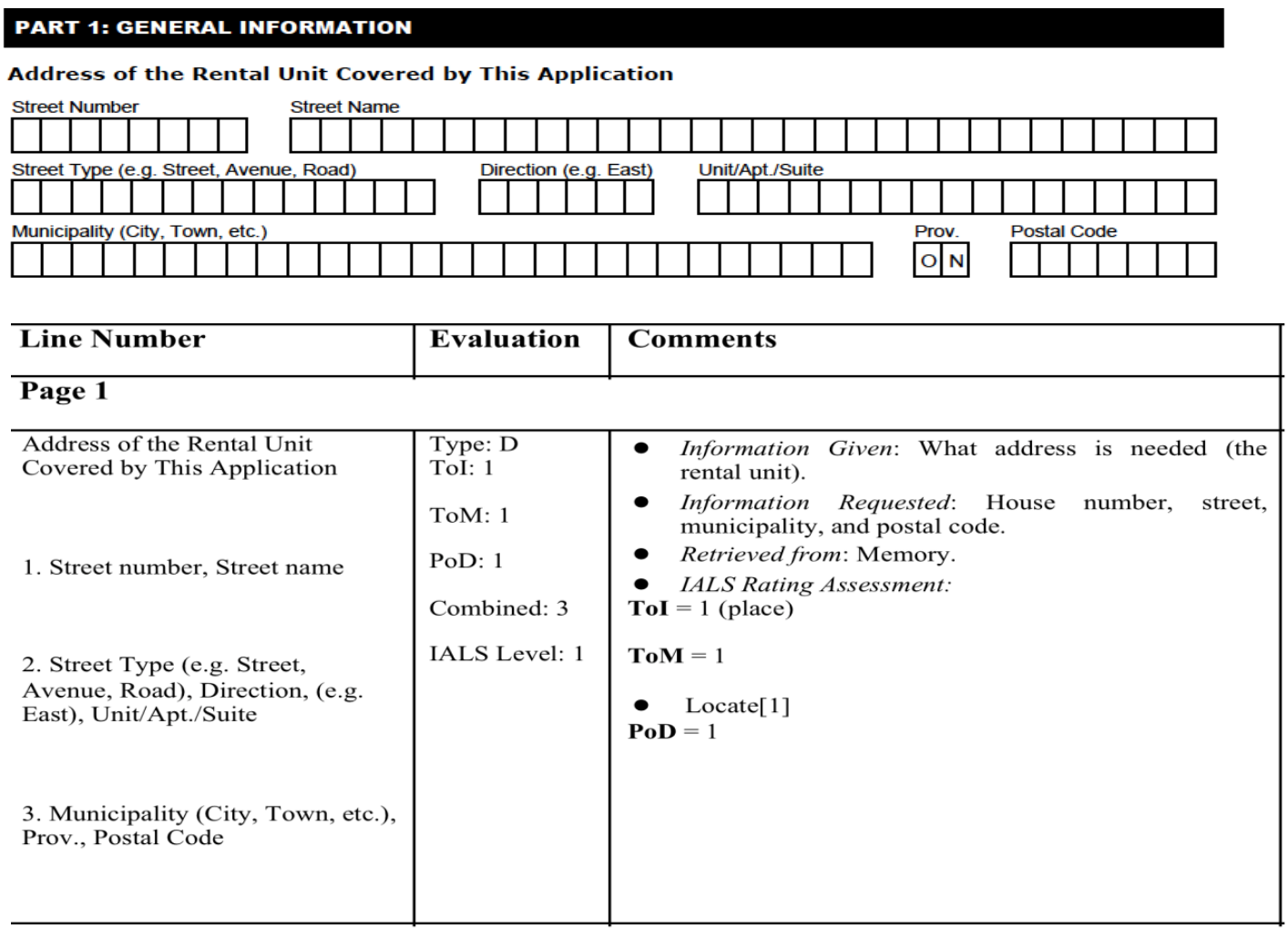


This example is taken from the Application about Tenant Rights and involves the user indicating the location of the rental unit. The top image is the relevant portion of the form and the bottom image is the evaluation of this field using the rating tool. The entries in the evaluation column indicate as follows:

- "Type: D" = the field involves a document task.

- "ToI: 1 " = rating of 1 is given for type of information because the field requests highly concrete information (that is, a specific place).

- "ToM: 1 " = a rating of 1 is given for type of match because this is a simple locating task.

- "PoD: $1 "=$ the field contains no plausible distractors.

- "Combined: 3 " = the total score for the section is 3 .

- "IALS Level: 1 " notes that only a very low literacy level is required for the task.

Example 2 (difficult task)

Have the parties arbitrated or agreed to arbitrate any matter involved in this case?

No

Yes (Give date of agreement and family arbitration award, if any.)

\begin{tabular}{|c|c|c|}
\hline $\begin{array}{l}\text { 22. Have the parties arbitrated or } \\
\text { agreed to arbitrate any matter } \\
\text { involved in this case? }\end{array}$ & $\begin{array}{l}\text { Type: D } \\
\text { ToI: } 2 \\
\text { ToM: } 9 \\
\text { PoD: } 2 \\
\text { DC: } 0 \\
\text { Combined: } 13 \\
\text { IALS Level: } 5\end{array}$ & $\begin{array}{l}\text { - Information Given: Has there been any agreement } \\
\text { to arbitrate any matters of the case? } \\
\text { Information Requested: Yes or no. If yes, what } \\
\text { was the date of agreement and any decisions } \\
\text { made? } \\
\text { - Retrieved from: Documents, memory. } \\
\text { ToI }=2 \text { (yes / noting Assessment: } \\
\text { ToM = } 9 \\
\text { - Integributes) } \\
\text { inference for given info[1] }+ \text { high inference for } \\
\text { requested info[4] } \\
\text { This information could be located from memory } \\
\text { or documents. } \\
\text { Inference is required to determine what is meant } \\
\text { by "arbitration" and "award." An individual may } \\
\text { need to look these legal terms up and the proper } \\
\text { definition may be difficult to find or understand. } \\
\text { It is necessary to cycle through any previous } \\
\text { agreements and compare/contrast what is in that } \\
\text { document with what is in dispute in this case. } \\
\text { Doing so accurately may be a difficult and } \\
\text { tedious task. } \\
\text { PoD = } 2 \text { It may be difficult to determine whether a } \\
\text { previous arbitration agreement is relevant to the } \\
\text { current proceedings. There is a possibility that } \\
\text { important information will be left out. } \\
\text { This field does not require a guide. } \\
\text { - }\end{array}$ \\
\hline
\end{tabular}


This example is taken from the Divorce Application form, requiring the user to indicate whether the parties have arbitrated or agreed to arbitrate any matter involved in the case.

The entries in the evaluation column indicate as follows:

- "Type: D" = the field involves a document task.

- "ToI: 2 " = rating of 2 is given for type of information because the field requires the user to fill in an attribute (yes/no) and this requires filling in "information that is less concrete" (to use the language in the rating tool).

- "ToM: 9" = a rating of 9 is given because the task requires the user to "integrate" as it would require the user to cycle through any previous agreements and compare and contrast what is in dispute in his case. Additionally, the user is required to infer what is meant by "arbitration" and "award" in the question. Depending on what previous agreements are in place, inferences may be needed to determine if such agreements are relevant to the question being asked.

- "PoD: 2 " = a rating of 2 is given because it is possible that confusion will result when the user reviews previous agreements and attempts to determine if they are relevant.

- "Combined: 13 " = the total score for the section is 13 .

- "IALS Level: 5" notes that a high literacy level is required for the task.

\section{Example 3 (another difficult task)}




\begin{tabular}{|c|c|c|}
\hline $\begin{array}{l}28 \text {. Give details of the order that } \\
\text { you want the court to make. }\end{array}$ & $\begin{array}{l}\text { Type: } \\
\text { ToI: } 4 \\
\text { ToM: } 10 \\
\text { PoD:1 } \\
\text { Combined: } 15 \\
\text { IALS Level: } 5\end{array}$ & $\begin{array}{l}\text { Information Given: You must provide details of what } \\
\text { type of claims you would like to make. } \\
\text { Information Requested: Explain what type of orders } \\
\text { you would like to ask the court to make including } \\
\text { amounts of support under each relevant category. } \\
\text { Retrieved from: Form instructions, memory, inference. } \\
\text { IALS Rating Assessment: } \\
\text { ToI }=4 \text { (explanation) } \\
\text { ToM }=10 \\
\text { Generate[5] + low inference for given info[1] + high } \\
\text { inference for requested info[ } 4] \\
\text { A response must be generated based on an individual's } \\
\text { circumstances, requiring high inference, expert legal } \\
\text { knowledge of what type of orders can be made, and an } \\
\text { ability to explain this effectively. } \\
\text { The applicant must presumably provide reasons for } \\
\text { each order that he or she requested in the previous } \\
\text { section. } \\
\text { Determining what information is relevant here requires } \\
\text { high inference. } \\
\text { PoD }=1 \\
\text { Document Complexity }=0\end{array}$ \\
\hline
\end{tabular}

This example is also taken from the Divorce Application and requires the user to provide details as to what order the user wants the court to make. The entries in the evaluation column indicate as follows:

- "Type: $\mathrm{D}$ " = the field involves a document task.

- "ToI: $4 "$ = rating of 4 is given for type of information because the field requires the user to provide an explanation and this requires filling in "very abstract information" (to use the language in the complexity rating tool).

- "ToM: $10 "$ " a rating of 10 is given because the task requires the user to "generate" and requires a high level of inference to determine what information would be relevant.

- "PoD: 1 " = the field contains no plausible distractors.

- "Combined: 15 " = the total score for the section is 16 .

- "IALS Level: 5" notes that a very high literacy level is required for this task. 
Appendix C: Estimated IALS Ratings for Each Task

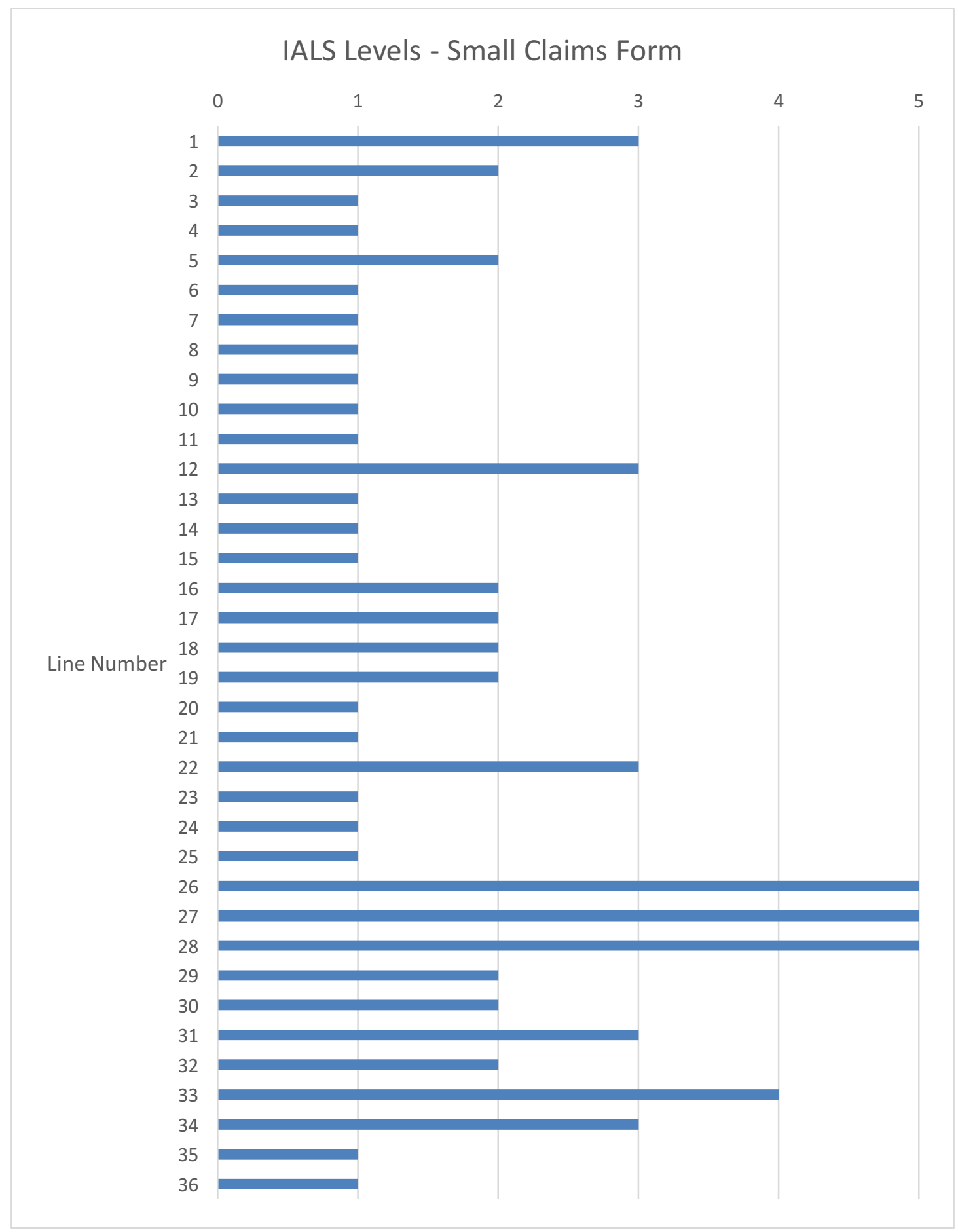


T2 Landlord Tenant Form - IALS Levels

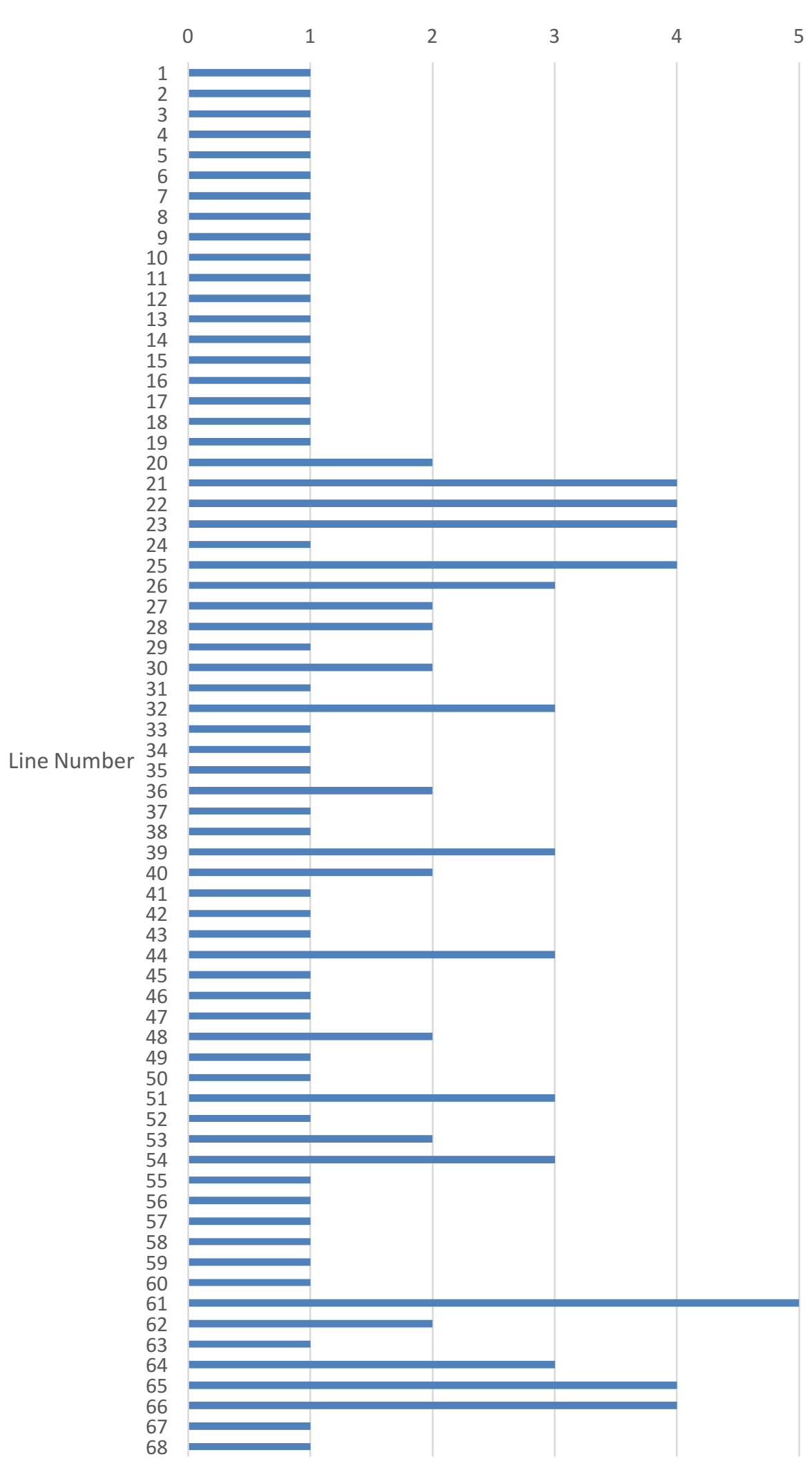




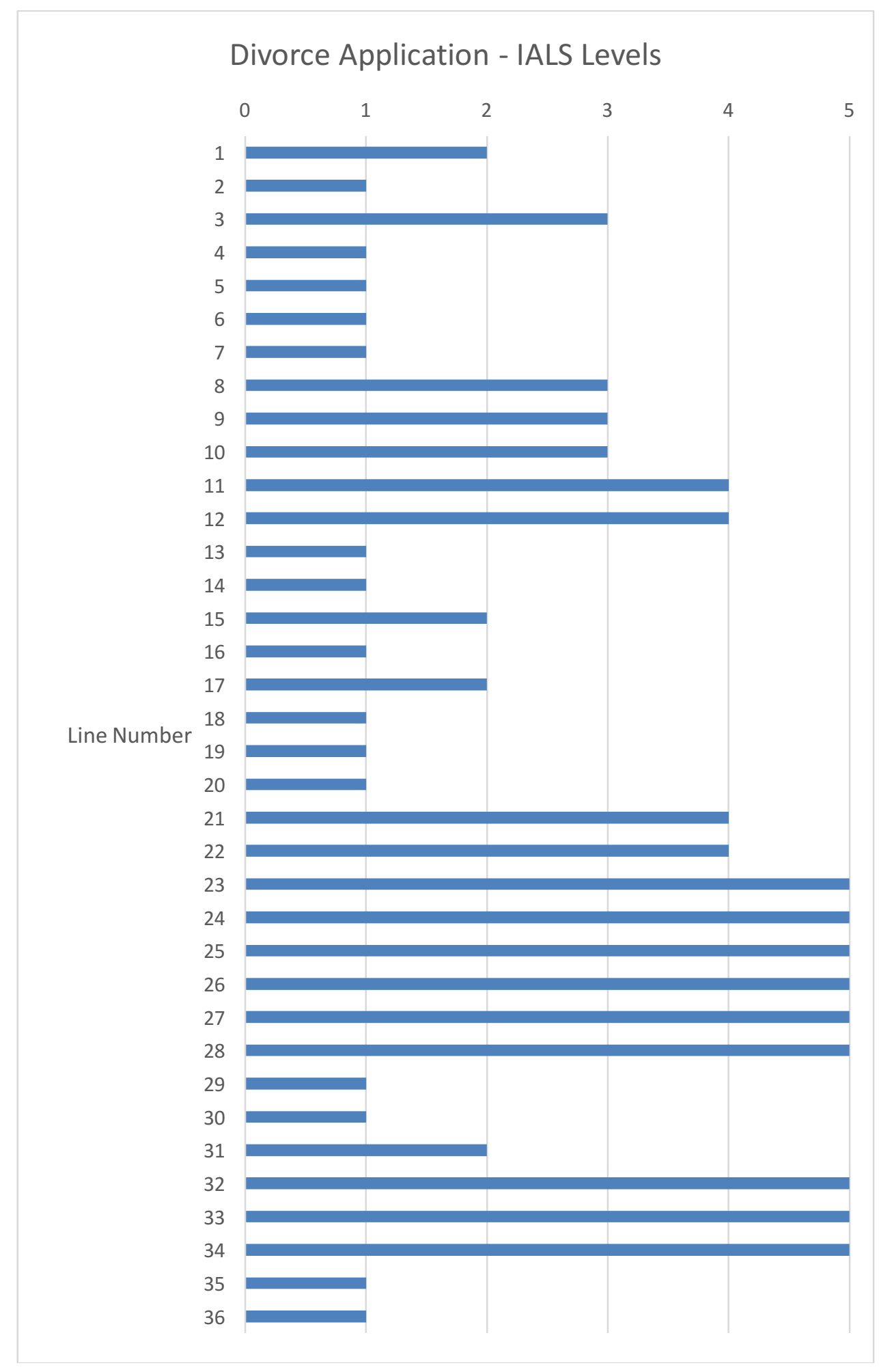




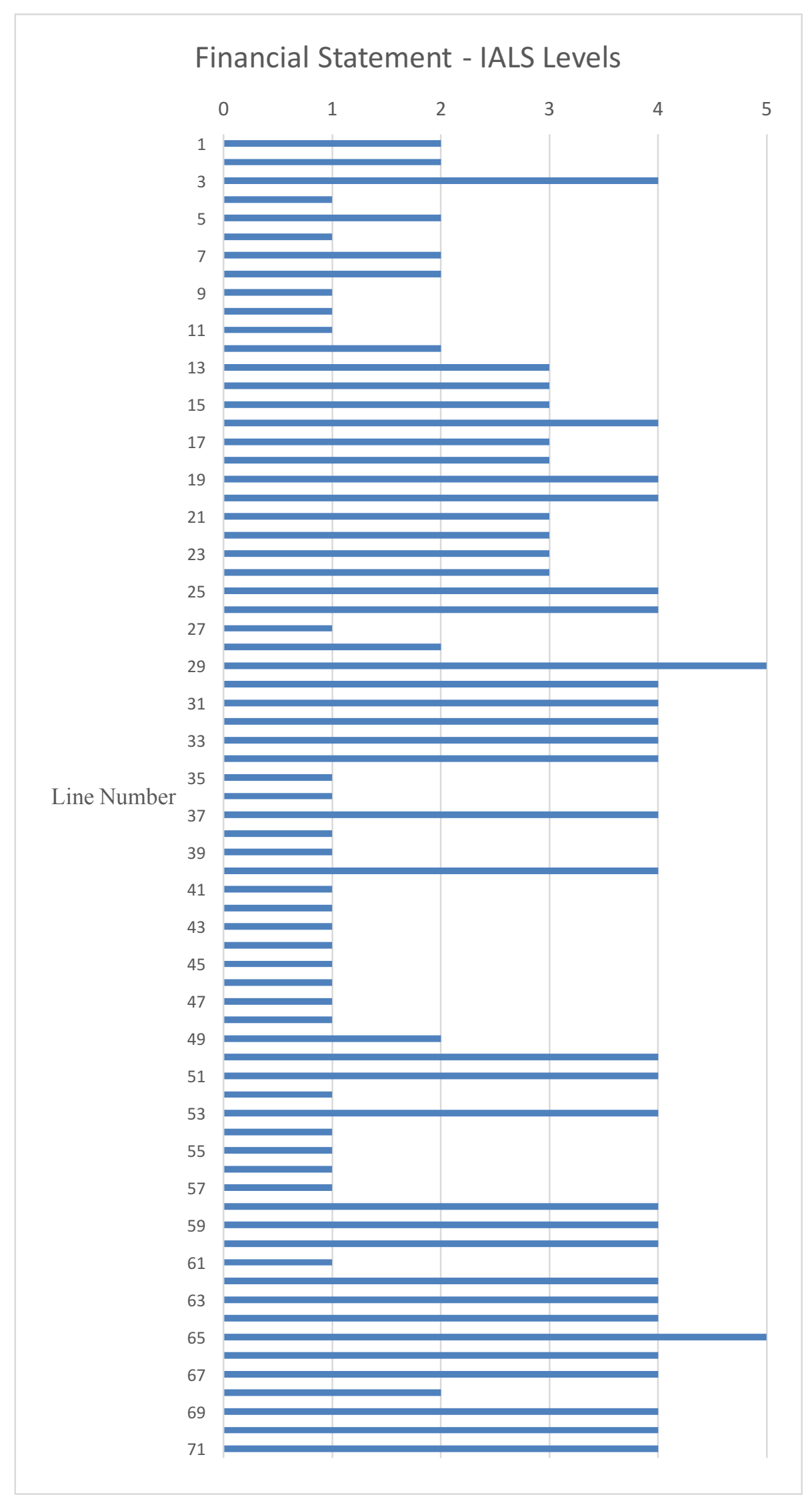


Financial Statement (Continued) - IALS Level

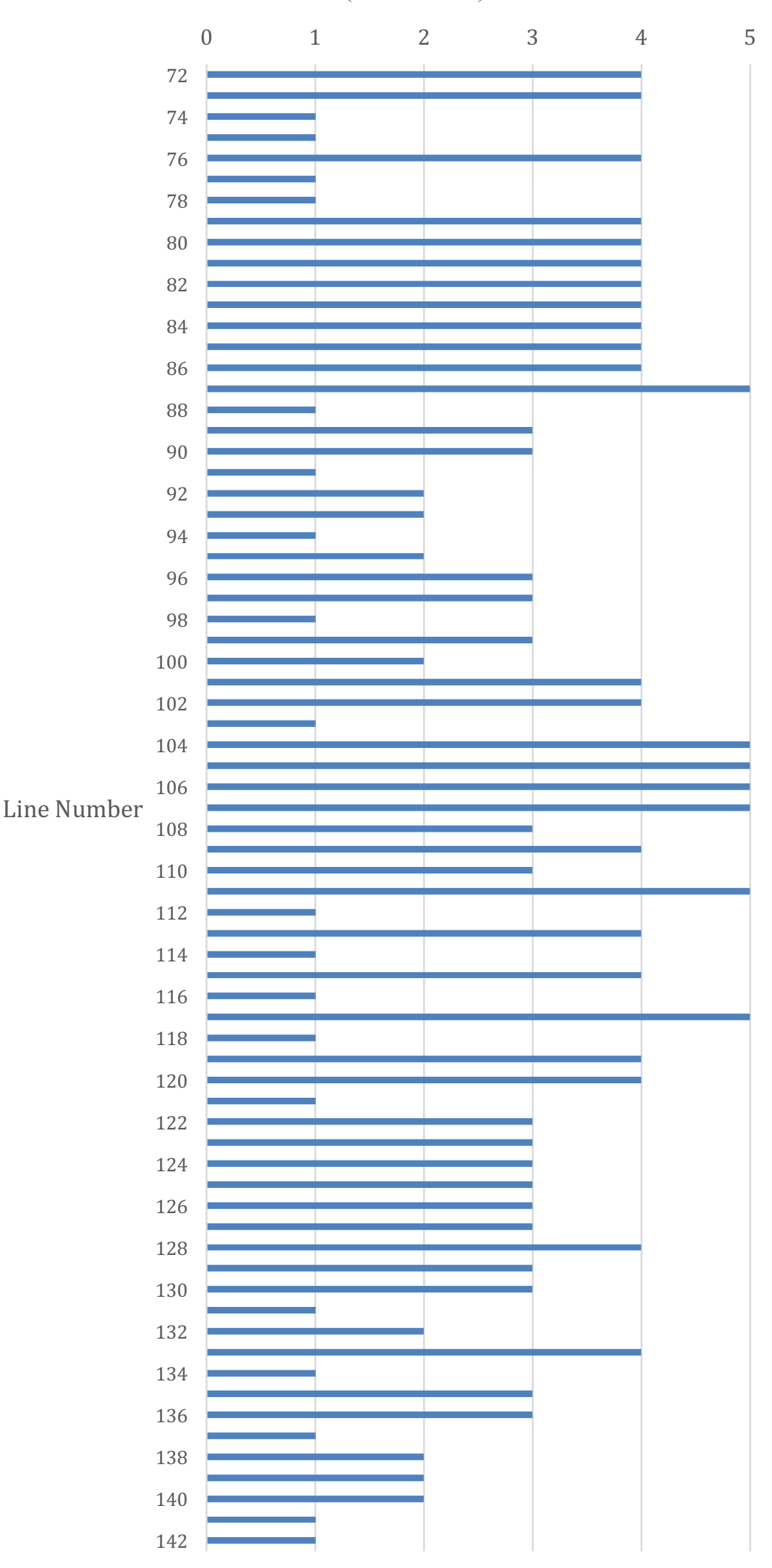

